\title{
High-Efficiency Thermodynamic Power Cycles for Concentrated Solar Power Systems
}

\author{
Marc T. Dunham \\ Sandia National Laboratories \\ Brian Iverson \\ Brigham Young University - Provo, bdiverson@byu.edu
}

Follow this and additional works at: https://scholarsarchive.byu.edu/facpub

Part of the Heat Transfer, Combustion Commons

\section{Original Publication Citation}

Vol. 30, pp. 758-770

\section{BYU ScholarsArchive Citation}

Dunham, Marc T. and Iverson, Brian, "High-Efficiency Thermodynamic Power Cycles for Concentrated Solar Power Systems" (2014). Faculty Publications. 1585.

https://scholarsarchive.byu.edu/facpub/1585

This Peer-Reviewed Article is brought to you for free and open access by BYU ScholarsArchive. It has been accepted for inclusion in Faculty Publications by an authorized administrator of BYU ScholarsArchive. For more information, please contact ellen_amatangelo@byu.edu. 


\title{
High-Efficiency Thermodynamic Power Cycles for Concentrated Solar Power Systems
}

\author{
Marc T. Dunham ${ }^{\mathrm{a}}$ and Brian D. Iverson ${ }^{\mathrm{a}, \mathrm{b} \dagger}$ \\ ${ }^{a}$ Sandia National Laboratories, Albuquerque, NM, 87185 \\ ${ }^{b}$ Brigham Young University, UT, 84602
}

†Author to whom correspondence should be addressed: bdiverson@byu.edu 


\section{Abstract}

This paper provides a review of high-efficiency thermodynamic cycles and their applicability to concentrating solar power systems, primarily focusing on high-efficiency single and combined cycles. Novel approaches to power generation proposed in the literature are also highlighted. The review is followed by analyses of promising candidates, including regenerated He-Brayton, regenerated $\mathrm{CO}_{2}$-Brayton, $\mathrm{CO}_{2}$ recompression Brayton, steam Rankine, and $\mathrm{CO}_{2}-\mathrm{ORC}$ combined cycle. Steam Rankine is shown to offer higher thermal efficiencies at temperatures up to about $600{ }^{\circ} \mathrm{C}$ but requires a change in materials for components above this temperature. Above this temperature, $\mathrm{CO}_{2}$ recompression Brayton cycles are shown to have very high thermal efficiency, potentially even exceeding $60 \%$ at $30 \mathrm{MPa}$ maximum pressure and above $1000{ }^{\circ} \mathrm{C}$ maximum temperature with wet cooling. An estimate of a combined receiver and power cycle operating temperature is provided for the cycles considered and compared to the traditional approach of optimization based on the Carnot efficiency. It is shown that the traditional approach to optimizing the receiver and turbine inlet temperatures based on Carnot is generally not sufficient, leading to an optimum temperature shift of more than $100{ }^{\circ} \mathrm{C}$ from the Carnot case under various conditions. 


\section{Introduction}

Among renewable energy approaches, concentrating solar power (CSP) holds significant promise for adoption as a utility-scale solution in an environment of increasing energy demand, limited fossil fuel resources, national incentives for renewable energy deployment, and growing concerns over the environmental implications of the continued use of traditional fuel sources like coal, gas, and nuclear fission material. CSP technology shares the clean energy portfolio primarily with wind turbines, hydroelectric generators, and solar photovoltaics. Each technology has specific advantages and may be particularly well-suited to one climate or application over another, such as using photovoltaics in dry sunny areas or hydro power near a natural moving water source. However, it is common for renewable energy sources to be intermittent, which limits their penetration into utility markets as well as their reliability for on-demand operation. CSP distinguishes itself by being dispatchable through the use of cost-effective thermal energy storage, exhibits versatility in its output capability (heat, mechanical work, or electric power), and enables integration with existing turbomachinery hardware.

While the benefit of an abundant renewable energy source through a solar-driven power cycle is clear, there exists the unavoidable complication that direct solar radiation is only available during the day, and even then is often interrupted by weather transients. Electric power loads are not confined to daylight hours; thus, the instantaneous supply from an intermittent source may not always meet the electricity demand. Thermal storage facilitates a power production shift from available daytime hours to accommodate diurnal cycling and weather transients. CSP with thermal energy storage is viewed as an enabling technology allowing greater market penetration for all renewable energy technologies [1-3]. Thermal storage technologies have been developed to allow for a range of storage times, from short transient buffers to longer-term nighttime 
storage [4], with well-designed CSP plants demonstrating full 24-hour operation [5]. Historically, the development of CSP technology has required a balance between capital cost, performance, and suitability for a particular application. While parabolic trough technologies are the most mature, the relative capital cost of thermal storage in power tower construction has been estimated to be about half that for parabolic trough construction (6\% vs. 12\%) [6]. Additionally, power tower systems are capable of achieving higher temperatures and efficiencies due to increased concentration ratios. As thermal storage is being identified as a significant differentiator between CSP and other renewable technologies, high-efficiency tower systems are gaining favor over the more mature trough technology, which is limited to lower solar fluxes and temperatures. Use of molten salts as a sensible storage medium is the standard against which current storage options are compared. However, many molten salts solidify at temperatures above ambient, causing blockage and potential damage to the piping and heat exchangers. An active area of CSP research involves fluid materials that can accommodate a broad range of temperatures necessary for CSP plant receivers [7].

Despite the unique benefits of thermal storage, CSP has been viewed to be a relatively costly renewable energy option. Techno-economic analyses have shown a significant potential for cost reduction through efficiency improvement of the power block [8-10]. Due to the widespread use of turbomachinery and heat engine technology, CSP is somewhat unique in the renewable energy portfolio in that it stands to benefit from economies of scale and technological advances in the larger coal, natural gas, and nuclear industries. While modern subcritical steam cycles (the most common thermodynamic power cycle to date for CSP) may be limited to thermal efficiencies up to approximately 42\% [9], supercritical steam cycles have been developed with thermal efficiencies exceeding 47\% [11]. Combined cycles, which use the rejected heat from a high- 
temperature cycle to drive a lower-temperature cycle to supplement the power output, typically offers higher thermal efficiencies (potentially exceeding 60\%) and have been used in traditional power cycles for decades [12]. Such high-performance cycles have been shown or considered to be adaptable to CSP systems [13-15], and represent an important step in reducing the levelized cost of electricity and promoting CSP technology as a true competitor to traditional methods for utility-scale power generation. Despite the demonstrated benefits to optimization of the power block, solar receiver and optical concentrator design are very popular subsets of CSP research and constitute a bulk of recent reviews [16-18].

This work reviews a variety of thermodynamic cycle configurations, including standalone, combinatorial, and other novel cycles, which could be driven by existing concentrating solar technologies to meet the U.S. Department of Energy's SunShot Initiative target of $>50 \%$ thermal efficiency in an effort to reduce the cost of solar energy [19]. A thermodynamic analysis of a select group of promising cycles is presented for varying temperatures, pressures, and parameters including the use of wet- and dry-cooling technology in an effort to guide future work in the pursuit of high-efficiency CSP.

\section{Review of power cycles}

The power block can be realized by a variety of different thermodynamic cycles, which may be particularly suited to different applications and designs. A brief review of high-efficiency single cycles, combined cycles, and novel cycle approaches is provided in this section, followed by information on the effects of wet- and dry-cooling on the power block. This review provides a basis for the comparative analysis that follows. 


\subsection{High-efficiency single cycles}

Single cycles, i.e. a single Rankine or Brayton power cycle, represent the simplest thermal power plant configurations, and are the baseline in identifying high-efficiency systems. A basic Rankine cycle consists of four stages: compression of the liquid working fluid to high pressure, heating and subsequent vaporization of the working fluid driven by a heat source, expansion to lower pressure through a turbine to generate mechanical work, and cooling of the working fluid back to the initial state. A Brayton cycle behaves similarly except that the working fluid remains in the gas (or supercritical) phase throughout the cycle. Brayton cycles are able to operate at much higher temperatures, therefore increasing the potential thermal efficiencies following the maximum efficiency for a Carnot engine. Innovative receiver concepts have been proposed and demonstrated which can heat gases to temperatures above $1000{ }^{\circ} \mathrm{C}[20,21]$. However, the compression stage of gas-Brayton cycles requires much more power, reducing the net work of Brayton cycle engines.

Despite the existence of energy recovery devices such as feedwater heaters and regenerators, the maximum gross thermal efficiencies of subcritical steam Rankine cycles, used in solar facilities such as Solar One or SEGS typically run in the range of $37-42 \%[9,22]$. Subcritical steam Rankine cycles used for CSP parabolic trough have typically been limited to turbine inlet temperatures of less than $400{ }^{\circ} \mathrm{C}$ due to limitations of the oil heat transfer fluid and relatively low solar fluxes provided by the concentrating optics. Use of a molten salt working fluid or systems generating steam directly (without the use of an intermediate heat transfer fluid) have been explored, which can raise the turbine inlet temperature above $400{ }^{\circ} \mathrm{C}$ in trough systems [23,24]. 
Molten-salt power tower plants are limited to receiver outlet temperature of approximately 565$600{ }^{\circ} \mathrm{C}$ and employ heat exchangers to produce superheated steam at $540{ }^{\circ} \mathrm{C}$ and 130 bar and reheated steam at $538{ }^{\circ} \mathrm{C}$ and 28 bar [25]. The resulting gross thermal efficiencies are typically $42 \%$ with wet cooling. Supercritical steam cycles have the potential to operate at higher temperatures and pressures, increasing the thermal efficiency to above 45\% [11,26,27]. Operating with steam in the supercritical regime allows for higher temperatures and fluid behavior that shares the compressibility traits of a liquid while avoiding complications due to multi-phase heat exchangers. However, concern has been expressed when steam temperatures exceed $627{ }^{\circ} \mathrm{C}$ due to the limitations of standard ferritic steels; these higher temperatures are expected to require the use of high-nickel alloys [27]. Organic Rankine Cycles (ORC) have been studied in-depth for their use in medium-temperature and waste heat recovery applications $[28,29]$, though they typically have efficiencies on the order of $10-20 \%$ and are most often used as bottoming cycles when the exit stream from a high temperature cycle still possesses high availability.

Higher efficiencies on the order of 50\% are predicted for advanced, high-power, multiple-reheat, helium Brayton cycles which could operate with a turbine inlet temperature from $750-850{ }^{\circ} \mathrm{C}$ [26]. These temperatures are significantly higher than those used in subcritical steam Rankine cycles but are achievable by current high-concentration solar tower technology. Helium possesses good heat transfer characteristics which could be beneficial in the design of the solar receiver. Angelino and Invernizzi [30] note that the closed helium cycle could be useful in cogeneration applications, as the rejected heat is typically available at relatively high temperatures. 
Another single cycle that has been shown to potentially offer high efficiencies is the supercritical Brayton cycle, with special attention paid to carbon dioxide as the working fluid [31]. In the supercritical region, fluids exhibit compressibility and heat transfer characteristics more like liquids while still reaching high temperatures. This allows for reduced compressor work and more efficient regenerative heat exchange [32]. Angelino found that single-heating supercritical $\mathrm{CO}_{2}\left(\mathrm{~s}-\mathrm{CO}_{2}\right)$ cycles above $650{ }^{\circ} \mathrm{C}$ have a higher efficiency than reheat steam Rankine cycles [33]. Dostal et al. showed a thermal efficiency of $46.07 \%$ for a s- $\mathrm{CO}_{2}$ Brayton cycle with turbine inlet temperature of $550{ }^{\circ} \mathrm{C}$, and $49.25 \%$ for a helium Brayton cycle with turbine inlet temperature of $880{ }^{\circ} \mathrm{C}$ [34]. The volumetric flow rate for $\mathrm{s}-\mathrm{CO}_{2}$ is much less than that for helium (by approximately a factor of 5) leading to smaller turbomachinery requirements. Moisseytsev and Sienicki examined a s- $\mathrm{CO}_{2}$ cycle for a lower-temperature nuclear-driven process which operated between $31.25{ }^{\circ} \mathrm{C} / 7.4 \mathrm{MPa}$ and $470{ }^{\circ} \mathrm{C} / 20.0 \mathrm{MPa}$ with a thermal efficiency of $39.1 \%$ [35]. An increase in thermal efficiency to $43.1 \%$ was found by reducing the minimum temperature and pressure to $20{ }^{\circ} \mathrm{C} / 5.75 \mathrm{MPa}$ so that the cycle operated as a condensation cycle. However, the low condensation temperature requires heat rejection to a relatively lowtemperature that may not be possible in environments where the ambient temperature is high. Nevertheless, the s- $\mathrm{CO}_{2}$ Brayton cycle has been considered for use in CSP with initial studies of transient behavior by a cyclic, solar-driven heat source recently being published by Iverson et al. [31]. Garg et al. [36] concluded that by operating in the supercritical regime, the same thermal efficiency can be achieved with a lower maximum temperature, suggesting the potential for cost savings or further performance increases. Ma and Turchi suggested a modular tower design to capitalize on small s- $\mathrm{CO}_{2}$ turbomachinery and place the entire power block on the tower (with multiple neighboring towers and fields) rather than pipe high-pressure fluid between them or 
introduce complications of a single large tower [37]. Not restricted to high-temperature use, Singh et al. [38] have also studied the use of $\mathrm{s}-\mathrm{CO}_{2}$ in parabolic trough concentrators. It must also be noted that the region around the $\mathrm{CO}_{2}$ critical point is marked by rapid fluctuations in thermodynamic properties which may present a challenge in the design and operation of turbomachinery, particularly for a transient heat source like concentrated solar energy. Furthermore, pressure losses in the piping of $\mathrm{s}-\mathrm{CO}_{2}$ systems have been found to have a more significant effect on thermal efficiency than for a steam cycle [39]. The combination of very high temperatures and penalties due to off-design operation may limit the applicability of s-CO $\mathrm{CO}_{2}$ to CSP systems with stabilizing thermal storage.

\subsection{Combined cycles}

A combined cycle utilizes multiple thermodynamic cycles: one primary high-temperature cycle (topping cycle) and one or more lower-temperature cycles (bottoming cycles) driven by the heat rejected from the higher-temperature cycle. While significant steps have been made towards high-efficiency single cycles, it has been widely-believed that operation above the $50 \%$ thermal efficiency mark (demonstrated in combined cycles since the late 1980s [12,20]) may require the implementation of binary or combined cycles [40-42], though it has been suggested that advanced $\mathrm{s}-\mathrm{CO}_{2}$ and helium Brayton cycles could potentially reach into the $50 \%$ range. Furthermore, combined cycles have been shown to be techno-economically effective, despite increased capital costs $[15,43]$. Brayton-topped, combined cycles allow for optimum use of highly concentrated solar energy where the ideal operating temperature is beyond what can be used in sub-critical Rankine cycles [44]. 
A common combined cycle configurations consists of a topping Brayton cycle with a bottoming ORC for waste heat recovery $[13,45,46]$. A study of air-ORC combined cycles showed $50 \%$ thermal efficiency was possible for gas turbine inlet temperatures above $1027{ }^{\circ} \mathrm{C}$, with the best combination at this temperature being air-toluene with an efficiency of 53.75\% [45]. The peak temperature of toluene in the bottoming cycle was found to be $297{ }^{\circ} \mathrm{C}$ at the turbine inlet. A high-temperature combined cycle based on a closed-loop $\mathrm{CO}_{2}$ Brayton cycle and driven by concentrated solar radiation was examined and found to produce a thermal efficiency of $47.51 \%$ for a turbine inlet temperature of $827^{\circ} \mathrm{C}$ when combined with an isopentane bottoming cycle [13]. A variety of working fluids proposed for use in low-temperature or bottoming cycles were compared by Chen et al. [28]. It was determined that the critical temperature and classification as a "dry" or "wet" fluid (defined by the slope of the saturated vapor curve on the $T-s$ diagram) were significant in determining the fluid's suitability for a given application. Further, dry fluids actually perform better when not superheated at the turbine inlet, which can reduce the need for additional heating sections.

Johnson examined power cycle performance with a nuclear source and concluded that a single $\mathrm{CO}_{2}$ or cascaded (multiple) s- $\mathrm{CO}_{2}$ cycle had benefits over a combined helium Brayton and supercritical steam Rankine in terms of performance and turbomachinery size, although the s$\mathrm{CO}_{2}$ technology is the least mature and may not be available for near-term application [47]. For a topping cycle turbine inlet temperature of $850{ }^{\circ} \mathrm{C}$, Johnson calculated the net thermal efficiency to be $49.8 \%$ for a cascaded s- $\mathrm{CO}_{2}$ configuration.

Alkali metals have been proposed for high-temperature topping cycles in a Rankine-Rankine combined cycle configuration [30]. This system provides good temperature-matching with a bottoming steam cycle and high heat transfer coefficients because of the liquid metal phase 
change in the condenser. Thermal efficiencies of an alkali metal Rankine topping cycle and steam Rankine bottoming cycle have been shown to reach $56 \%$ for $1000{ }^{\circ} \mathrm{C}$ maximum working fluid temperature, with the potential to reach $60 \%$. However, turbomachinery for the metal vapor cycles is estimated to be large, with a $50 \mathrm{MW}$ turbine tip diameter of about $3.9 \mathrm{~m}$ for potassium and $2.8 \mathrm{~m}$ for rubidium [30].

\subsection{Novel cycles}

Novel thermodynamic cycles not typically used in the power cycle market have also been explored for CSP, though primarily still planned for use in combined cycles. A classic fringe cycle is the water-ammonia power cycle popularized by Kalina [48]. This cycle utilizes an adjustable mixture of two fluids with different boiling points to fit the fluid thermodynamics to the heat source, allowing for higher thermal efficiencies. This type of cycle has been proposed for the bottoming side of a combined cycle with a working fluid property tuned to the topping cycle heat rejection $[8,49,50]$. However, experimental studies and simulations have shown performance benefits of only around 3\% in using a Kalina bottoming cycle compared with an ORC, while requiring more complex equipment [28].

Kribus proposed a system involving a triple "cycle" for solar energy conversion that is much like a typical combined cycle but with an additional energy conversion above the topping cycle. Feeding the topping cycle is the waste heat from a magneto-hydro-dynamic (MHD) cycle, which uses extremely hot ionized air heated to approximately $2000{ }^{\circ} \mathrm{C}$ to directly induce an electric current using magnets [51]. Very high efficiencies are possible in this configuration, theoretically approaching 70\%. However, concentration ratios of approximately 10,000 suns are also needed, 
requiring a power tower system with a complex and high-precision secondary concentrator, as well as very high-temperature receiver materials.

Organic Flash Cycles (OFC) for CSP have also been suggested for power generation with a medium-temperature heat source [52]. The OFC uses organic fluids, similar to the ORC, for the inherent advantages of a dry fluid as well as increased turbomachinery performance from the higher molecular weight/complexity when compared with water. In an OFC all of the heat is provided in the liquid phase, and the saturated liquid is throttled to a saturated vapor state at lower pressure. The vapor is then passed through a turbine to generate power. This approach reduces heating irreversibilities due to the temperature profile mismatch during isothermal/isobaric phase change, allowing for closer matching of the source and sink temperature profiles as in a single-phase heat exchanger. The OFC was shown to have a higher utilization efficiency (work output over supply heat availability) than basic ammonia-water Rankine and transcritical $\mathrm{CO}_{2}$ cycles, favoring its use as a bottoming cycle.

\subsection{Water use}

Often, the most available solar resource for CSP technology is present in desert regions with little available fresh water for cooling. For this reason, it is beneficial to make use of dry-cooling methods for thermal power cycles. Wet-cooled CSP installations can require significant quantities of water for operation; approximately 760-920 gal/MWh for trough systems and 750 gal/MWh for tower systems [53]. While dry-cooling technologies can reduce water use by more than $90 \%[54,55]$, the technology currently costs about 3.3 times more than water cooling equipment and contributes to increased electricity costs [14,56]. The effects of dry-cooling 
compared to water cooling are estimated to reduce the annual energy production by $4-9 \%$ and annual solar-to-electric conversion efficiency by $0.5-0.7 \%$ for trough systems [57]. Ambient temperature variations can dramatically affect the efficiency of dry-cooling methods, and have been found to have a significant effect on off-design operation of combined-cycle plants [58]. Experiments in the Southwest United States with hybrid wet and dry cooling systems have shown promising results, with $50 \%$ water usage of a wet cooling system maintaining $99 \%$ of the performance of a full wet-cooled facility, and $10 \%$ water usage maintaining $97 \%$ energy performance [53]. Power tower plants currently being built in the US $\left(392 \mathrm{MW}_{\mathrm{e}}\right.$ Ivanpah Solar Electric Generating Station using direct steam and $110 \mathrm{MW}_{\mathrm{e}}$ SolarReserve Crescent Dunes using molten salt) are being built to utilize dry-cooling to reduce water consumption. While it is true that the initial capital cost of wet cooling equipment is lower than that of dry cooling equipment, it is worth considering the continuing cost of water, particularly in regions like the Southwest United States where demand is already overwhelming supply from many regional aquifers. Holbert and Haverkamp suggested that the overall cost of dry cooling technology to be lower than that of wet cooling after 20 years of operation [54].

\section{High efficiency cycles for solar}

In addition to providing an overview of high-performance cycle studies, this work is intended to present analyses for a select group of thermodynamic power cycles which have the potential to reach thermal efficiencies near the 50\% target set by the Department of Energy and the Sunshot Initiative. The present study is focused on the analysis of regenerative Brayton, recompression Brayton, steam Rankine, and combined Brayton-ORC thermodynamic cycles. These cycles are 
chosen due to their demonstrated or suggested high thermal efficiencies as well as the current use or development of the required turbomachinery. The cycles analyzed represent standard configurations for each type. The software package Engineering Equation Solver (EES) [59] and its library of equations of state is utilized to provide the working fluids' thermophysical properties. It is assumed that the wet- and dry-bulb temperatures utilized by Kolb [60] (22 and 43 ${ }^{\circ} \mathrm{C}$, respectively) are representative of conservative ambient temperatures for wet- and drycooling methods near Barstow, CA. Assuming a $10{ }^{\circ} \mathrm{C}$ pinch point temperature difference in the ambient heat exchangers, conditions are modeled for wet- and dry-cooling of the cycles. The conditions of analysis for each cycle are described below. For all cycles, the thermal efficiency is calculated as the ratio of net work output to heat input at the receiver.

\subsection{Regenerative Brayton cycle}

The first cycle considered is the closed regenerative Brayton cycle with one stage of intercooling. A component schematic of the cycle is presented in Fig. 1. A fluid at the minimum system temperature enters the first-stage compressor at state (1) and is compressed to higher

pressure and temperature at state (2). A heat exchanger (HEX) removes heat from the fluid before it enters the second-stage compressor at state (3). This process is known as intercooling, and serves two primary purposes: it reduces the total work required for compression and reduces the compressed fluid outlet temperature which allows for more substantial regeneration. The compressed gas then enters the cold side of the regenerator at state (4) where it is preheated before entering the receiver at state (5). Now at its highest temperature, the compressed gas enters the turbine at state (6) where it is expanded to low pressure. At state (7), the hot turbine 
outlet stream enters the hot side of the regenerator, preheating the cold-side fluid. Finally, the gas enters a heat exchanger at state (8) through which it is returned to the minimum cycle temperature.

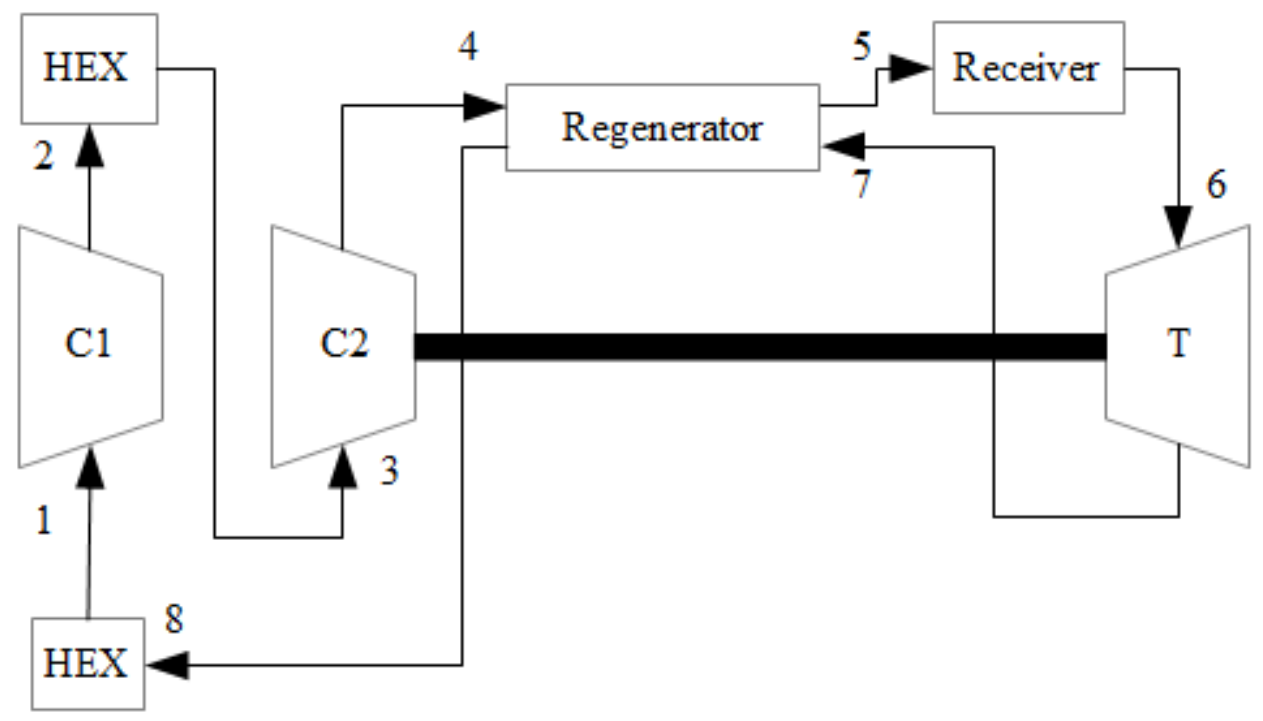

Fig. 1. Component schematic of regenerative Brayton cycle.

The compression ratio of each compressor in a two-stage intercooled process with known minimum and maximum pressures and a constant (i.e. not fractional) pressure drop in the intercooler can be derived as:

$$
p_{\mathrm{R}, \mathrm{stage}}=\frac{p_{\text {loss }, \mathrm{HEX}}+\sqrt{\left(p_{\text {loss } \mathrm{HEX}}\right)^{2}-4 p_{\min } p_{\max }}}{2 p_{\min }}
$$

The effectiveness of the regenerator is calculated using the state enthalpies [61]: 


$$
\varepsilon_{\text {regen }}=\frac{h_{5}-h_{4}}{h_{7}-h_{\left(T_{4}, p_{7}\right)}}
$$

The term $h_{\left(T_{4}, p_{7}\right)}$ is commonly assumed to be the same as $h_{4}$ for gas turbine analysis [62]. This is an acceptable approximation for fluids behaving like ideal gases, such as for air and helium turbines at reasonable pressures, because the enthalpy of an ideal gas is dependent only on temperature. However, for cycles operating near a fluid's critical point, such as high-pressure carbon dioxide cycles, the definition in Eq. (2) must be used or non-physical consequences may result, including violation of the second law of thermodynamics at the outlets of the regenerator. The assumptions used for analysis of the regenerative Brayton cycle are outlined in Table 1.

Table 1. Regenerated Brayton cycle simulation parameters.

\begin{tabular}{llll}
\hline Cycle Parameter & Value $(\mathbf{H e})$ & Value $\left(\mathbf{C O}_{\mathbf{2}}\right)$ & Reference \\
\hline$\eta_{\text {compressor }}$ & $85.9 \%$ & $80 \%$ & {$[13,45]$} \\
\hline$\eta_{\text {turbine }}$ & $93 \%$ & $90 \%$ & {$[13,45]$} \\
\hline$\varepsilon_{\text {regen }}$ & $95.6 \%$ & $85 \%$ & {$[13,45]$} \\
\hline$\eta_{\text {shaft }}$ & $98 \%$ & same & {$[45]$} \\
\hline$p_{\text {loss,receiver }}$ & $5 \%$ & same & {$[49]$} \\
\hline$p_{\text {loss,HEX }}(\mathrm{MPa})$ & 0.05 & same & assumed \\
\hline$T_{1}\left({ }^{\circ} \mathrm{C}\right)$ & $32($ wet-cooled $)$ & same & {$[58]$} \\
& $53($ dry-cooled) & & \\
\hline$T_{6}\left({ }^{\circ} \mathrm{C}\right)$ & $500-1100$ & same & assumed \\
\hline$p_{4}(\mathrm{MPa})$ & $10-30$ & same & assumed \\
\hline
\end{tabular}

The cycle is analyzed by selecting an outlet pressure $(10,15,20,25$, and $30 \mathrm{MPa})$ and maximum temperature $\left(500-1100{ }^{\circ} \mathrm{C}\right.$ ) and determining the pressure $p_{1}$ which provides the highest cycle thermal efficiency. The working fluids considered for operation are helium and $\mathrm{CO}_{2}$. 


\subsection{Recompression Brayton cycle}

In the recompression Brayton cycle, a fraction (typically in the range of 10-40\%) of the hot stream is returned to the minimum cycle temperature while the remaining flow bypasses the cooler and is recompressed from the higher temperature. Research of the recompression cycle has primarily been dedicated to supercritical $\mathrm{CO}_{2}$ [61]. Operating the compressor near the critical point reduces the work required for gas compression. This is due to the unique thermodynamic properties as the fluid transitions to supercritical state. A component schematic of the cycle is presented in Fig. 2. The assumptions used for analysis of the regenerative Brayton cycle are outlined in Table 2.

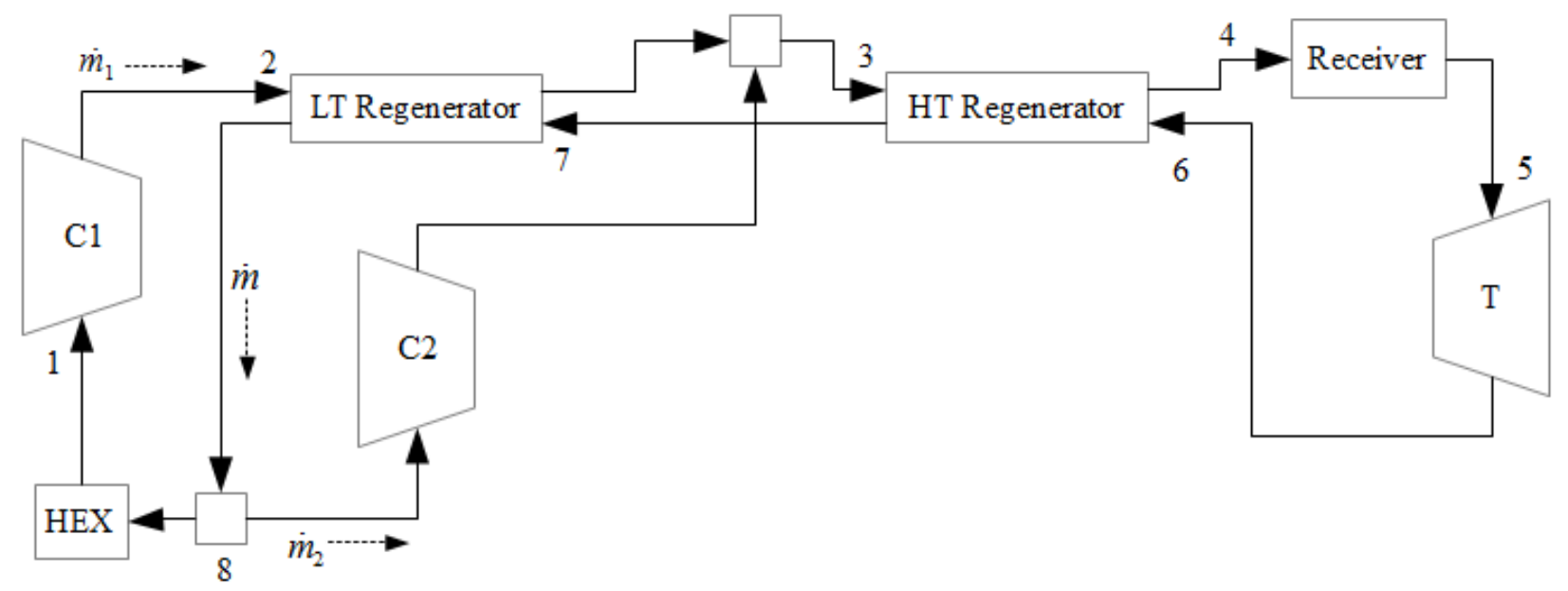

Fig. 2. Component schematic of recompression Brayton cycle. 
Table 2. Recompression $\mathrm{CO}_{2}$ Brayton cycle simulation parameters.

\begin{tabular}{lll}
\hline Cycle Parameter & Value & Reference \\
\hline$\eta_{\text {compressor }}$ & $89 \%$ & calculated from [59] \\
\hline$\eta_{\text {turbine }}$ & $90 \%$ & calculated from [59] \\
\hline$\varepsilon_{\text {regen,LT }}$ & $88 \%$ & calculated from [59] \\
\hline$\varepsilon_{\text {regen,HT }}$ & $97.6 \%$ & calculated from [59] \\
\hline$\eta_{\text {shaft }}$ & $98 \%$ & {$[59]$} \\
\hline$T_{5}\left({ }^{\circ} \mathrm{C}\right)$ & $500-1100$ & assumed \\
\hline$T_{1}\left({ }^{\circ} \mathrm{C}\right)$ & $32($ wet-cooled) & {$[58]$} \\
& $53($ dry-cooled) & \\
\hline$p_{2}(\mathrm{MPa})$ & $10-30$ & assumed \\
\hline$p_{\text {loss,receiver }}$ & $5 \%$ & {$[49]$} \\
\hline$p_{\text {loss,HEX }}(\mathrm{MPa})$ & 0.05 & assumed \\
\hline
\end{tabular}

\subsection{Combined Brayton-Rankine cycle}

The third major cycle configuration considered is the combined Brayton-Rankine cycle. The combined cycle makes use of the rejected heat from a regenerative Brayton cycle to drive a lowtemperature ORC. A component schematic of the cycle is presented in Fig. 3. 


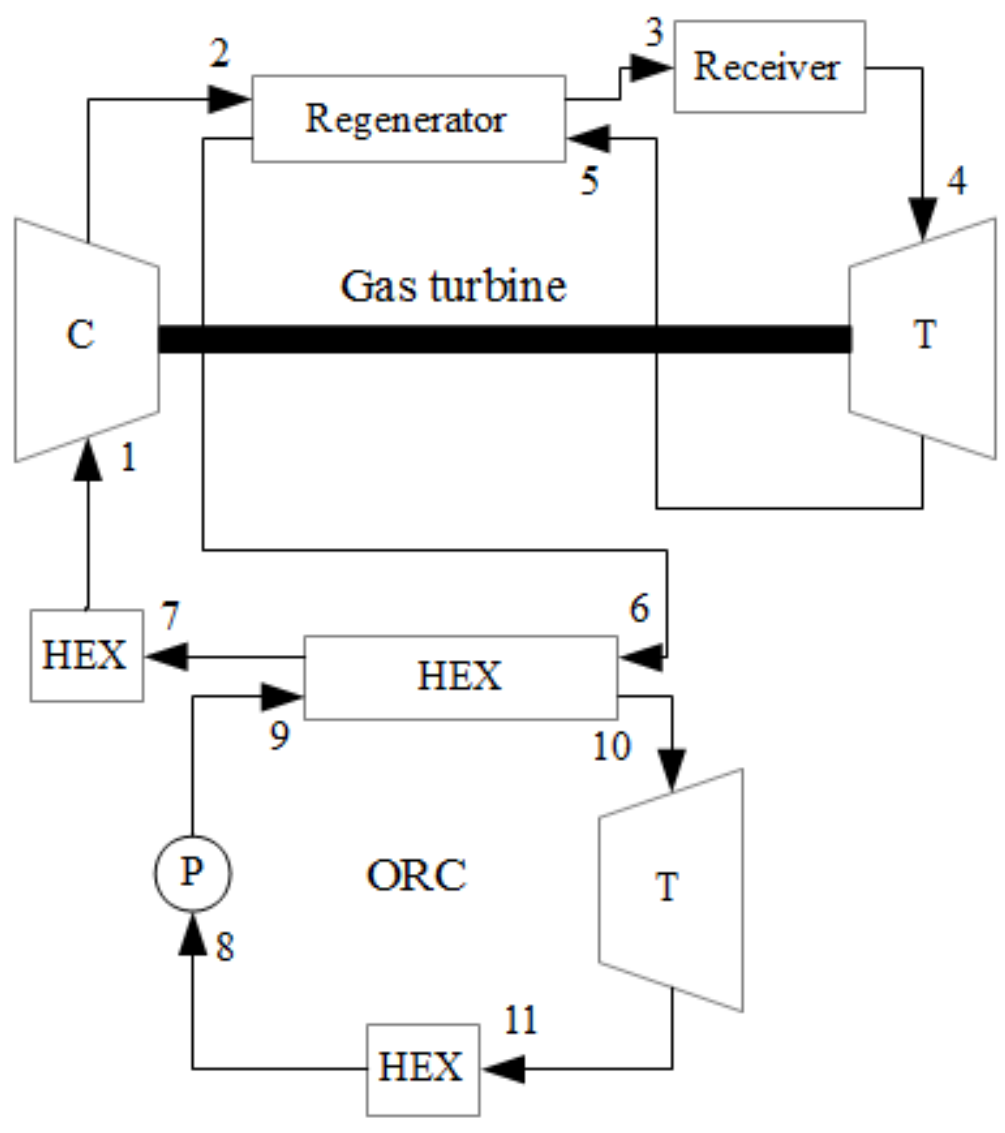

Fig. 3. Component schematic of combined Brayton-Rankine cycle.

The topping cycle in this system is a $\mathrm{CO}_{2}$ regenerated Brayton cycle without intercooling. The reason for neglecting an intercooling option is that the availability of the inlet stream to the heat exchanger at state (6) would be reduced, mitigating the benefits of the bottoming cycle. Analysis for a single maximum topping cycle pressure of $20 \mathrm{MPa}$ is presented due to the introduction of an additional degree of freedom from the ORC fluid selection, and for each temperature $T_{4}$, the pressure ratio for maximum topping cycle thermal efficiency is used. Then the conditions for the bottoming cycle are found by maximizing the combined cycle thermal efficiency as a function of $T_{7}$ and $p_{9}$. The maximum pressure of the ORC is limited to $2 \mathrm{MPa}$, according to the typical literature criterion for minimizing required safety measures and material expenses in ORCs [29]. The combined thermal efficiency of the cycles is calculated as: 


$$
\eta_{\text {combined }}=\frac{\dot{W}_{\text {net,top }}+\dot{W}_{\text {net,bottom }}}{\dot{Q}_{\text {in,top }}}
$$

Since the flow rates of the two cycles will vary with respect to each other, it is necessary to assume a power input to the topping cycle, taken to be $100 \mathrm{MW}_{\mathrm{t}}$. This assumption is in line with a typical power tower plant size but is used here primarily to fix the mass flow rates. Heat exchange between the top and bottom cycles is governed by the following energy balance:

$$
\dot{m}_{\text {top }}\left(h_{6}-h_{7}\right)=\dot{m}_{\text {bottom }}\left(h_{10}-h_{9}\right)
$$

For each iteration, the heat exchange length is discretized into 100 segments and the temperature difference is checked. A minimum pinch-point temperature difference of $10{ }^{\circ} \mathrm{C}$ is enforced in the solution procedure. The organic fluid is assumed to be in the saturated vapor state at the turbine inlet; Hung, et al. [63] noted that efficiency of an ORC with dry working fluid decreases with increasing turbine inlet temperature under superheat. Three organic fluids are examined in the bottoming cycle: R-245fa, isopentane, and n-Hexane. Steam Rankine is not considered for a bottoming cycle as the heat delivery is at temperatures below $370{ }^{\circ} \mathrm{C}$ suggesting that an ORC implementation will offer higher efficiency [63]. The assumptions used for analysis of the combined Brayton-Rankine cycle are outlined in Table 3. 
Table 3. Combined Brayton-Rankine cycle simulation parameters.

\begin{tabular}{lll}
\hline Cycle Parameter & Value & Reference \\
\hline$\eta_{\text {compressor }}$ & $80 \%$ & {$[13]$} \\
\hline$\eta_{\text {pump }}$ & $80 \%$ & {$[13]$} \\
\hline$\eta_{\text {turbine,top }}$ & $90 \%$ & {$[13]$} \\
\hline$\eta_{\text {turbine,bottom }}$ & $87 \%$ & {$[13]$} \\
\hline$\varepsilon_{\text {regen }}$ & $85 \%$ & {$[13]$} \\
\hline$\eta_{\text {shaft }}$ & $98 \%$ & {$[13]$} \\
\hline$p_{\text {loss,receiver }}$ & $5 \%$ & {$[49]$} \\
\hline$p_{\text {loss,HEX }}(\mathrm{MPa})$ & 0.05 & assumed \\
\hline$T_{4}\left({ }^{\circ} \mathrm{C}\right)$ & $500-1100$ & assumed \\
\hline$T_{1}\left({ }^{\circ} \mathrm{C}\right)$ & 32 (wet-cooled) & {$[58]$} \\
& $53($ dry-cooled) & \\
\hline$T_{8}\left({ }^{\circ} \mathrm{C}\right)$ & 32 (wet-cooled) & {$[58]$} \\
& 53 (dry-cooled) & \\
\hline$p_{2}(\mathrm{MPa})$ & 20 & assumed \\
\hline
\end{tabular}

\subsection{Steam Rankine cycle}

Finally, a steam Rankine cycle is considered. A component schematic of the cycle is presented in Fig. 4. For each temperature and pressure combination, the feedwater pressure is varied to optimize the flow split for the highest thermal efficiency. Modern supercritical steam plants are significantly more complex in reality than the system modeled here. Nevertheless, the results provide reasonable agreement with much more complex analyses and serve as a relative measure for comparison with the other cycles considered here. The present analysis covers a range from subcritical to transcritical operation. As the critical temperature and pressure of steam is 374.15 ${ }^{\circ} \mathrm{C}$ and 22.1 MPa, respectively, the steam cycle presented in this analysis reaches a supercritical state for $25 \mathrm{MPa}$ and $30 \mathrm{MPa}$ pressures. The assumptions used for analysis of the steam Rankine cycle are outlined in Table 4. 


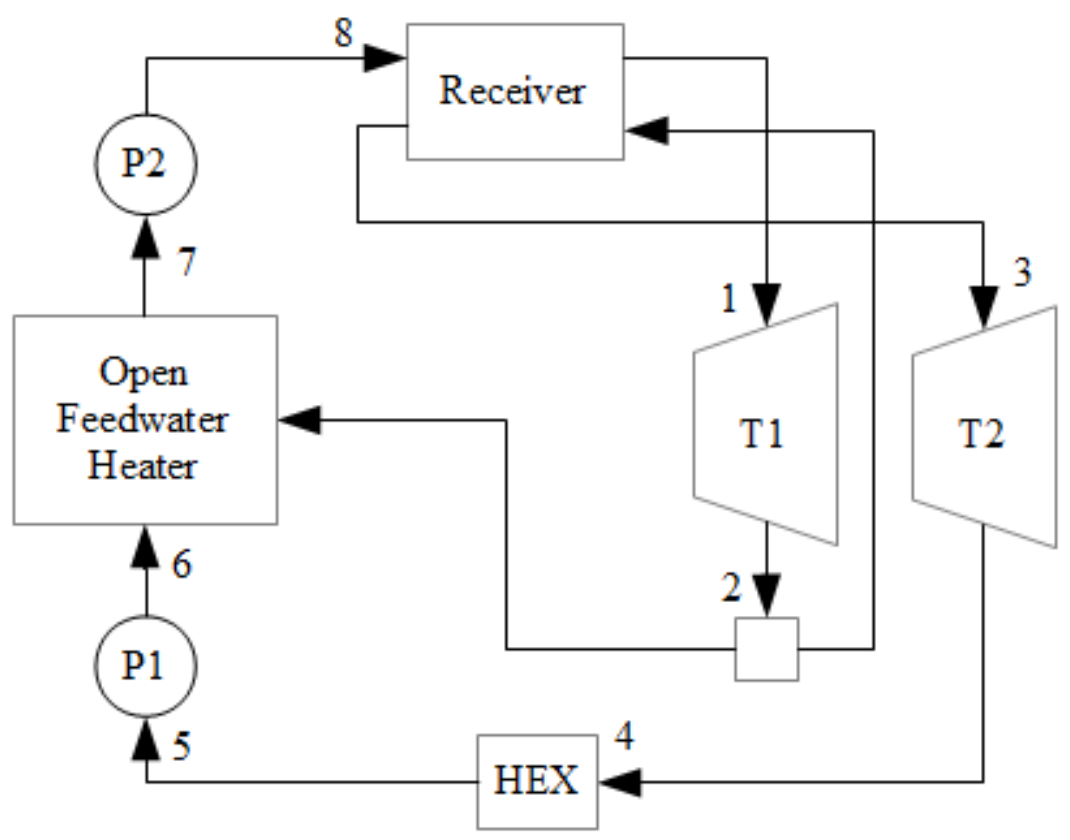

Fig. 4. Component schematic of steam Rankine cycle.

Table 4. Steam Rankine cycle simulation parameters.

\begin{tabular}{lll}
\hline Cycle Parameter & Value & Reference \\
\hline$\eta_{\text {pump, } \mathrm{HP}}$ & $85 \%$ & assumed \\
\hline$\eta_{\text {pump,LP }}$ & $85 \%$ & assumed \\
\hline$\eta_{\text {turbine,HP }}$ & $88 \%$ & calculated from [45] \\
\hline$\eta_{\text {turbine,LP }}$ & $91.7 \%$ & calculated from [45] \\
\hline$p_{\text {loss,receiver }}(\%)$ & 5 & assumed \\
\hline$p_{\text {loss, } \mathrm{HEX}}(\%)$ & 5 & assumed \\
\hline$T_{1}\left({ }^{\circ} \mathrm{C}\right)$ & $500-1100$ & assumed \\
\hline$T_{5}\left({ }^{\circ} \mathrm{C}\right)$ & 32 (wet-cooled) & {$[58]$} \\
& 53 (dry-cooled) & \\
\hline$p_{5}(\mathrm{MPa})$ & 0.00476 (wet-cooled) & $T_{5}$ saturation pressure \\
& 0.01431 (dry-cooled) & \\
\hline$p_{8}(\mathrm{MPa})$ & $10-30$ & assumed \\
\hline
\end{tabular}




\section{Cycle thermal efficiency results}

The first cycle analyzed is the regenerated He-Brayton cycle. The calculated thermal efficiency as a function of maximum temperature for a range of maximum pressures under wet-cooling conditions is plotted in Fig. 5a. It is readily seen that as long as the minimum pressure is free to vary, the maximum pressure has relatively minimal impact on the thermal efficiency under these operating conditions, rising from $55.0 \%$ at a maximum pressure of $10 \mathrm{MPa}$ to only $55.7 \%$ at 30 $\mathrm{MPa}$ for a maximum temperature of $1100{ }^{\circ} \mathrm{C}$. The maximum temperature has a significant impact on the system, causing the cycle thermal efficiency to rise from $29.3 \%$ at $500{ }^{\circ} \mathrm{C}$ to $55.7 \%$ at $1100{ }^{\circ} \mathrm{C}$ and $30 \mathrm{MPa}$ maximum pressure. This suggests that lower system pressures may be used with relatively minimal effects on performance, providing fewer constraints on thermal optimization of the solar receiver. 


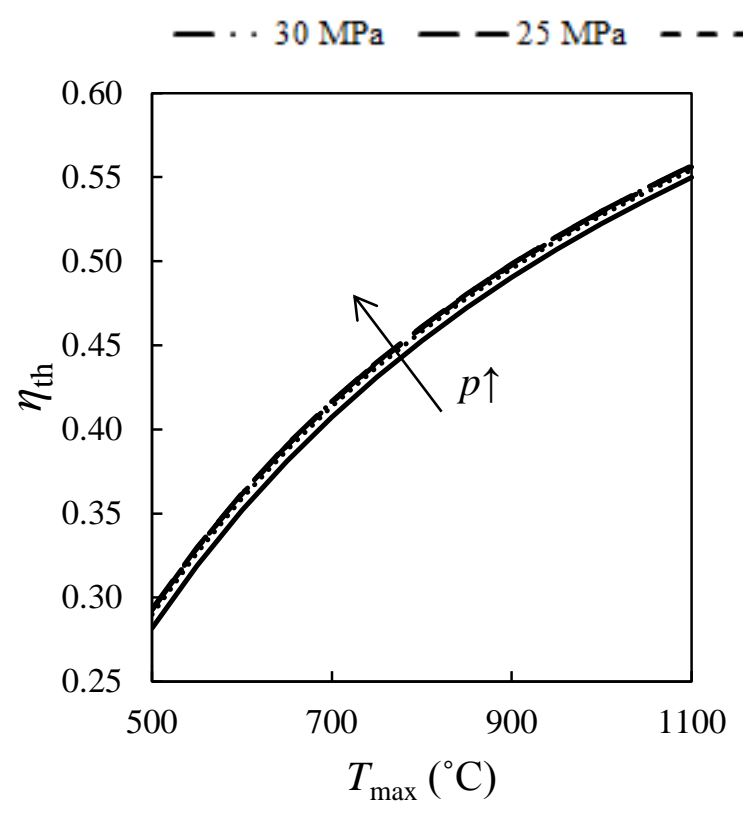

(a)

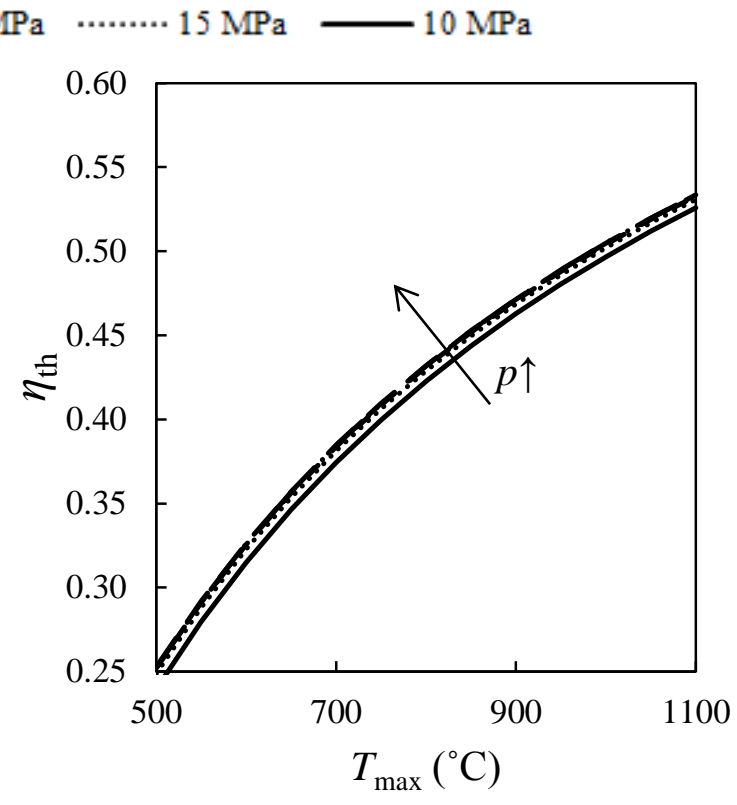

(b)

Fig. 5. Thermal efficiency of the regenerated He-Brayton cycle as a function of maximum temperature for different maximum pressures under (a) wet-cooling and (b) dry-cooling conditions.

The regenerated He-Brayton system is also analyzed under dry-cooling conditions, as plotted in

Fig. 5b. Again the relative importance of maximum temperature vs. maximum pressure is readily seen. The effects of dry cooling are more significant in systems running at lower maximum temperature; the thermal efficiency decreases from $29.3 \%$ to $25.2 \%$ at $30 \mathrm{MPa} / 500{ }^{\circ} \mathrm{C}$ vs. a drop from $55.7 \%$ to $53.4 \%$ at $30 \mathrm{MPa} / 1100{ }^{\circ} \mathrm{C}$. This represents a relative drop of $14.0 \%$ at 500 ${ }^{\circ} \mathrm{C}$ system temperature compared to $4.1 \%$ at $1100{ }^{\circ} \mathrm{C}$ system temperature. A thermal efficiency of $50 \%$ is realized at $30 \mathrm{MPa}$ operation and maximum cycle temperatures of approximately $900{ }^{\circ} \mathrm{C}$ for wet-cooling and $1000{ }^{\circ} \mathrm{C}$ for dry-cooling. 


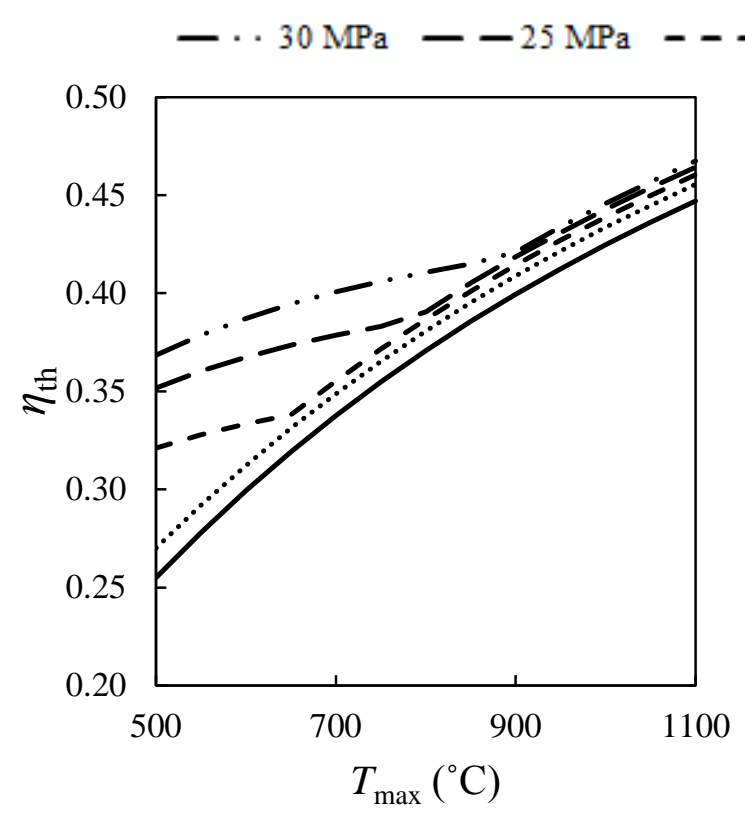

(a)

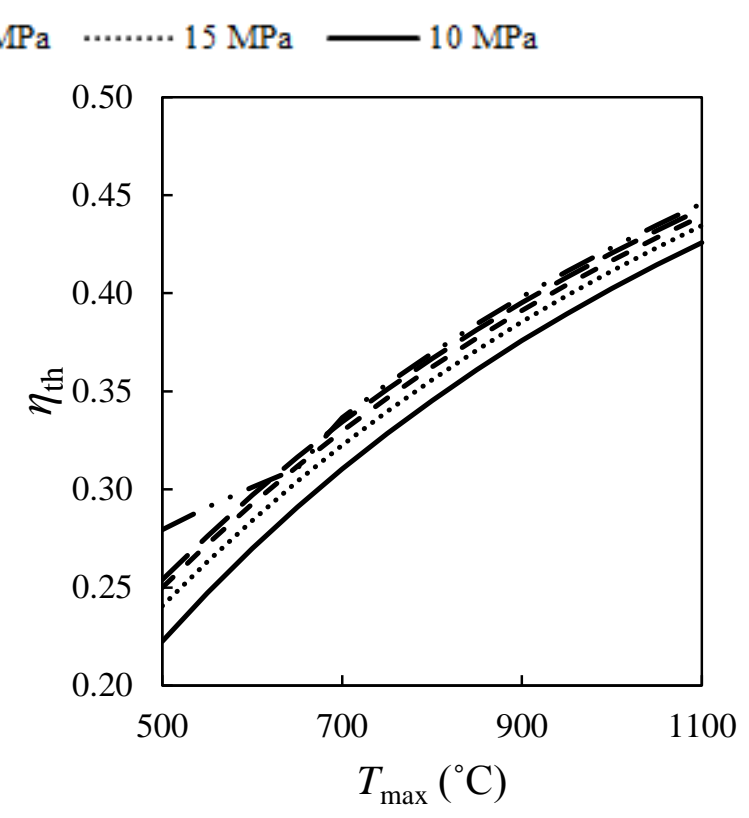

(b)

Fig. 6. Thermal efficiency of the regenerated $\mathrm{CO}_{2}$-Brayton cycle as a function of maximum temperature for different maximum pressures under (a) wet-cooling and (b) dry-cooling conditions.

The performance of the regenerated $\mathrm{CO}_{2}$-Brayton under wet-cooling conditions is plotted in Fig. 6a and illustrates interesting behavior; specifically, the efficiency lines diverge for lower maximum temperatures and higher maximum pressures. This is due to the fact that under specific conditions, the optimum pressure ratio for maximum efficiency sets the minimum pressure to be above the critical point, which results in reduced compressor work. In Fig. 6a, the flatter curve segments represent the regions where the fluid is in the supercritical state at the compressor inlet. Beyond a certain temperature, the benefits seen by maintaining the fluid in a supercritical state at the compressor inlet are lost and the optimum condition falls to the subcritical range. Supercritical operation provides significantly higher efficiency at the lower end of the temperature range analyzed here, however it is known that it can be difficult to maintain steady conditions for $\mathrm{CO}_{2}$ in the vicinity of the critical point where these advantages are observed. 
The analysis results for the regenerated $\mathrm{CO}_{2}$ Brayton system under dry-cooling conditions are provided in Fig. 6b. The transition from supercritical to subcritical conditions at the compressor inlet is apparent in the $30 \mathrm{MPa}$ case. However, the effects span a smaller range of temperatures with dry-cooling than for wet-cooling. Since $\mathrm{CO}_{2}$ behaves less like an ideal gas than He under most conditions, it is not surprising that the efficiency is more significantly-impacted by pressure. While a change from $30 \mathrm{MPa}$ to $10 \mathrm{MPa}$ for the $1100{ }^{\circ} \mathrm{C}$ case causes only a $1.5 \%$ performance drop for the He-Brayton cycle, the $\mathrm{CO}_{2}$-Brayton cycle sees a $4.5 \%$ drop. This suggests that more careful consideration of pressure may be required during design of the solar receiver for $\mathrm{CO}_{2}$ systems than $\mathrm{He}$ systems. The effects of dry-cooling reduce the thermal efficiency from $36.8 \%$ to $27.9 \%$ (24.2\% relative drop) in the $30 \mathrm{MPa} / 500{ }^{\circ} \mathrm{C}$ system, and from $46.7 \%$ to $44.6 \%$ (4.5\% relative drop) in the $30 \mathrm{MPa} / 1100{ }^{\circ} \mathrm{C}$ system. The high-temperature $\mathrm{CO}_{2}$-Brayton cycle shows more resilience to the effects of dry-cooling than does the He-Brayton cycle, though the thermal efficiencies are lower. Thermal efficiencies of $50 \%$ are not seen for any considered configuration of the regenerated $\mathrm{CO}_{2}$ Brayton cycle in this temperature range with the present assumptions. 


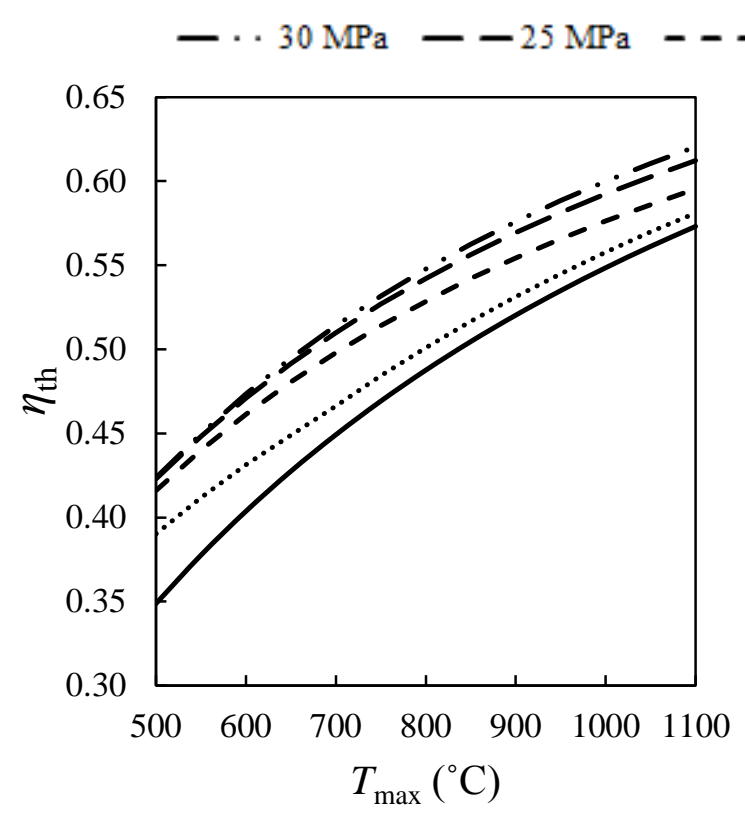

(a)

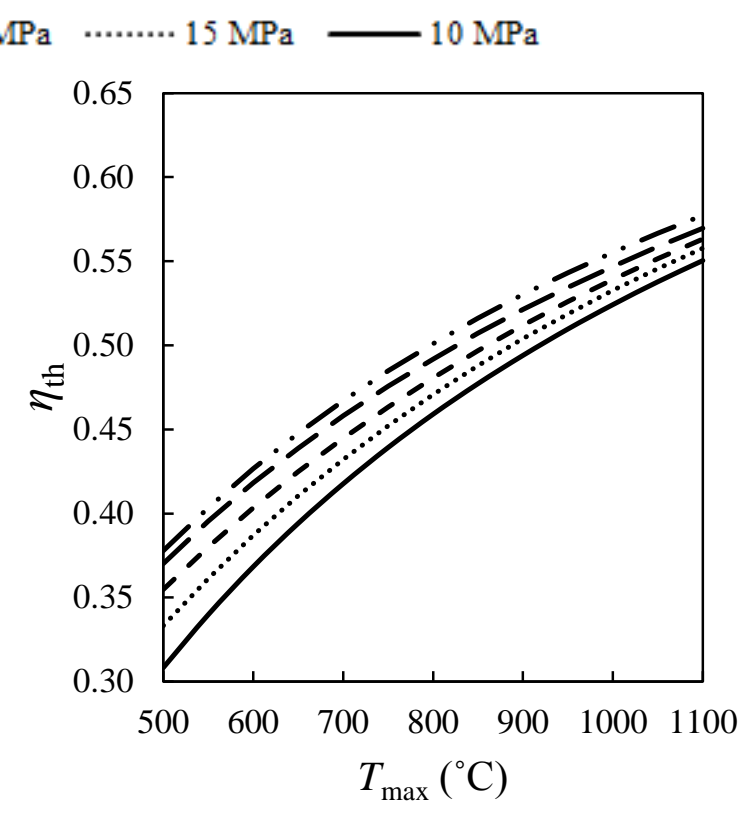

(b)

Fig. 7. Thermal efficiency of the $\mathrm{CO}_{2}$ recompression Brayton cycle as a function of maximum temperature for different maximum pressures under (a) wet-cooling and (b) dry-cooling conditions.

Performance results for the $\mathrm{CO}_{2}$ recompression Brayton cycle under wet-cooling conditions are given in Fig. 7a. The recompression cycle shows the potential for very high thermal efficiencies, particularly at high temperatures and pressures. A significant difference is seen in the curves for 10, 15, and $20 \mathrm{MPa}$ maximum pressure. This can be attributed to the fact that for the 10 and 15 MPa systems, very few of the compressor inlet conditions are in the supercritical state. For 20 $\mathrm{MPa}$, the compressor inlet condition is supercritical until a temperature of $1000{ }^{\circ} \mathrm{C}$. The compressor inlet condition is supercritical for the entire temperature range for the 25 and $30 \mathrm{MPa}$ maximum pressure systems.

The recompression cycle also exhibits high thermal efficiency under dry-cooling conditions and decreases from $62.1 \%$ to just $57.7 \%$ (relative drop of $7.1 \%$ ) at $1100{ }^{\circ} \mathrm{C} / 30 \mathrm{MPa}$. The lowtemperature end of the range sees a drop from $42.4 \%$ to $37.8 \%$ (relative drop of $10.8 \%$ ). The performance at $500{ }^{\circ} \mathrm{C}$ is significantly higher in the recompression cycle than seen in either of 
the regenerative Brayton cycles. At $30 \mathrm{MPa}, 50 \%$ thermal efficiency is reached with a maximum temperature of slightly above $650{ }^{\circ} \mathrm{C}$ for wet-cooling and slightly under $800{ }^{\circ} \mathrm{C}$ for dry-cooling.

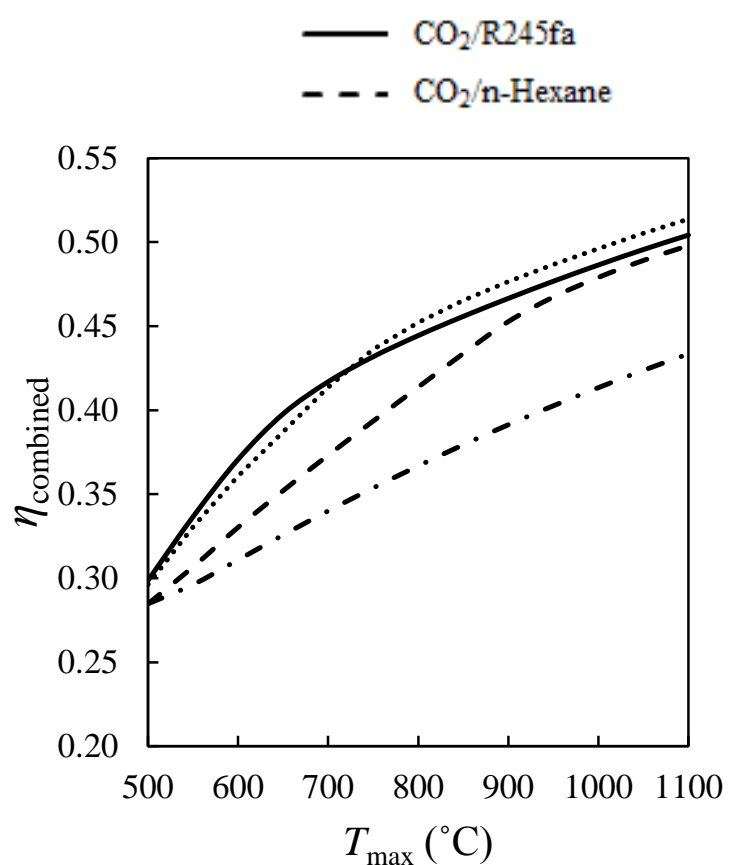

(a)
$\mathrm{CO}_{2} /$ Isopentane

- - $\mathrm{CO}_{2}$, no bottoming cycle

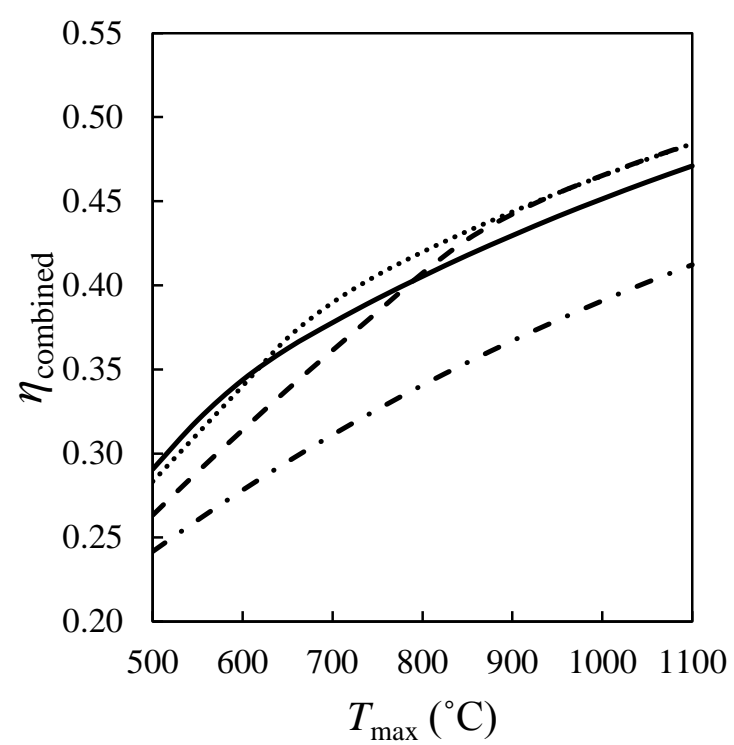

(b)

Fig. 8. Thermal efficiency of the combined Brayton-ORC system as a function of maximum temperature for 20 MPa maximum topping cycle pressure under (a) wet-cooling and (b) dry-cooling conditions.

The combined cycle analysis is presented in Fig. 8a for wet-cooling conditions. The combined cycles are compared with a standalone $\mathrm{CO}_{2}$ Brayton cycle in the topping cycle configuration shown in Fig. 3. The range of temperatures shown is $500-1100{ }^{\circ} \mathrm{C}$. It is noted that for $T_{\max }=500$ ${ }^{\circ} \mathrm{C}$ the temperature of heat supplied to the bottoming cycle was not sufficient to maintain a minimum $10{ }^{\circ} \mathrm{C}$ pinch point temperature difference when using $\mathrm{n}$-Hexane, therefore the performance is assumed to be the same as the single $\mathrm{CO}_{2}$ cycle. In all cases the maximum system pressure of the $\mathrm{CO}_{2}$ topping cycle is $20 \mathrm{MPa}$. The combined cycle approach offers a clear advantage to the standalone $\mathrm{CO}_{2}$ Brayton cycle, as the typically-rejected heat is utilized. Pairings with R245fa and Isopentane are superior to n-Hexane, though neither is consistently the top 
performer. This was also observed in the analysis by Chacartegui et al. [13]. Efficiency performance is high for the $\mathrm{R} 245 \mathrm{fa}$ and Isopentane pairings beyond $700{ }^{\circ} \mathrm{C}$, though $50 \%$ thermal efficiency is not achieved until approximately $1000{ }^{\circ} \mathrm{C}$ with Isopentane and $1100{ }^{\circ} \mathrm{C}$ with R245fa. The reader may notice that for each working fluid there is a temperature at which the efficiency levels off more rapidly. This is due to the fact that the optimum maximum pressure of the bottoming cycle passes the imposed 2.0 MPa limit, and therefore the overall efficiency is restricted slightly.

Combined cycle performance under dry-cooling conditions is shown in Fig. 8b. With drycooling, 50\% thermal efficiency is not reached for any of the pairings up to $1100{ }^{\circ} \mathrm{C}$. The upper limit of 2 MPa plays a role in the crossing of the efficiency curves. Particularly for R245fa, the peak efficiency occurs at a maximum pressure beyond $2 \mathrm{MPa}$, beginning at $600{ }^{\circ} \mathrm{C}$ for both wetand dry-cooling. By contrast, the optimal maximum pressure for Isopentane is below $2 \mathrm{MPa}$ until $800{ }^{\circ} \mathrm{C}$ with wet-cooling and until $700{ }^{\circ} \mathrm{C}$ with dry-cooling. The optimal maximum pressure for n-Hexane does not hit $2 \mathrm{MPa}$ until $900{ }^{\circ} \mathrm{C}$ for wet-cooling and $800{ }^{\circ} \mathrm{C}$ for dry-cooling. It therefore takes longer for Isopentane and n-Hexane systems to become limited by the maximum pressure, though R245fa shows more favorable thermodynamic performance at the lower temperatures and is the strongest performer in this region. 


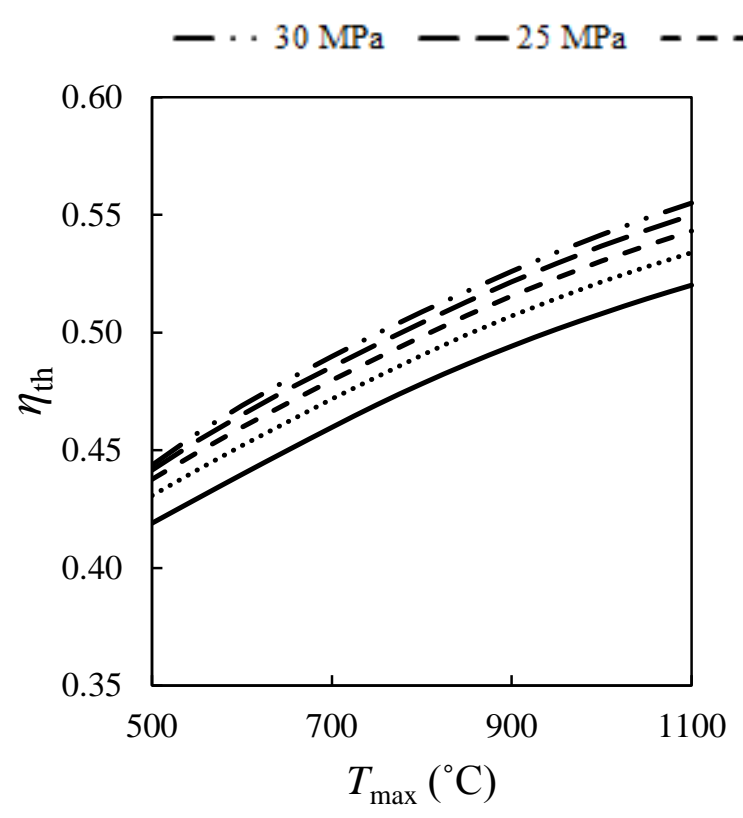

(a)

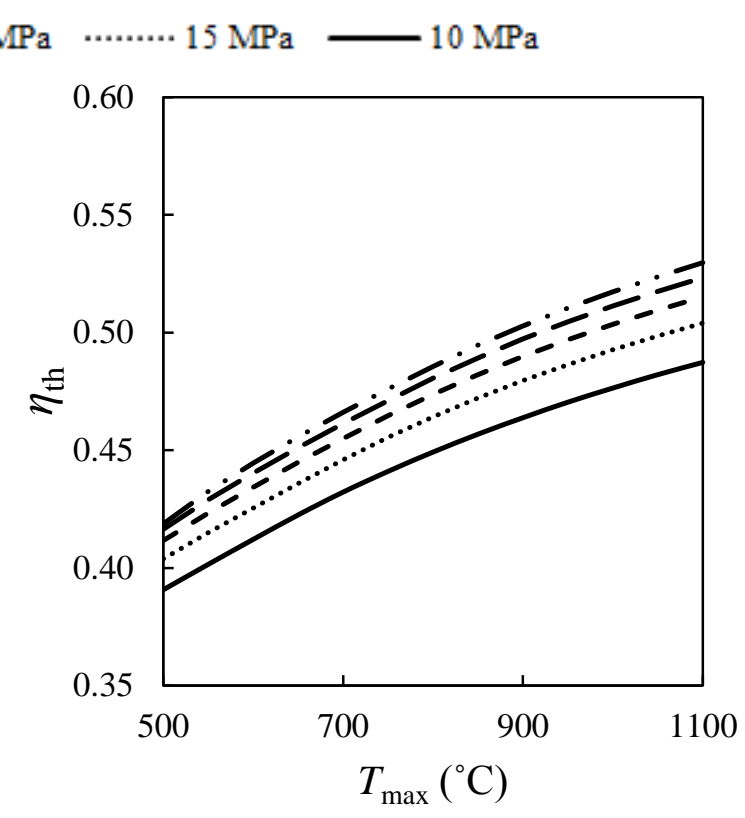

(b)

Fig. 9. Thermal efficiency of the steam Rankine cycle as a function of maximum temperature for different maximum pressures under (a) wet-cooling and (b) dry-cooling conditions.

Finally, the steam Rankine cycle with reheat and open feedwater system is considered. The thermal efficiency vs. maximum temperature is plotted in Fig. 9a for wet-cooling. The steam Rankine cycle shows favorable performance, particularly at lower maximum temperatures. The $30 \mathrm{MPa}$ system can quickly reach $50 \%$ thermal efficiency, at $750{ }^{\circ} \mathrm{C}$ for wet-cooling. However, as mentioned previously, current state of the art for steam turbine systems limits temperatures to a maximum of $627{ }^{\circ} \mathrm{C}$ due to material considerations. At $30 \mathrm{MPa}$, this corresponds to an efficiency of approximately $47.5 \%$.

The performance of the steam Rankine system with dry-cooling is illustrated in Fig. 9b. Dry cooling increases the temperature required for $50 \%$ thermal efficiency to just under $900{ }^{\circ} \mathrm{C}$ at 30 MPa. The efficiency at $627^{\circ} \mathrm{C}$ falls to $45.1 \%$. 


\section{Combined receiver and cycle thermal efficiency}

The thermal efficiency of the different configurations is compared directly as a function of maximum temperature for wet-cooling in Fig. 10a; a maximum pressure of $20 \mathrm{MPa}$ is assumed for all cases in this figure, and the Carnot efficiency is plotted for reference.

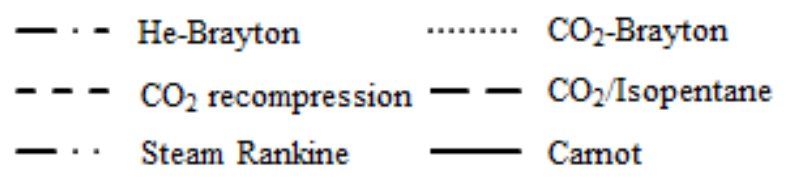

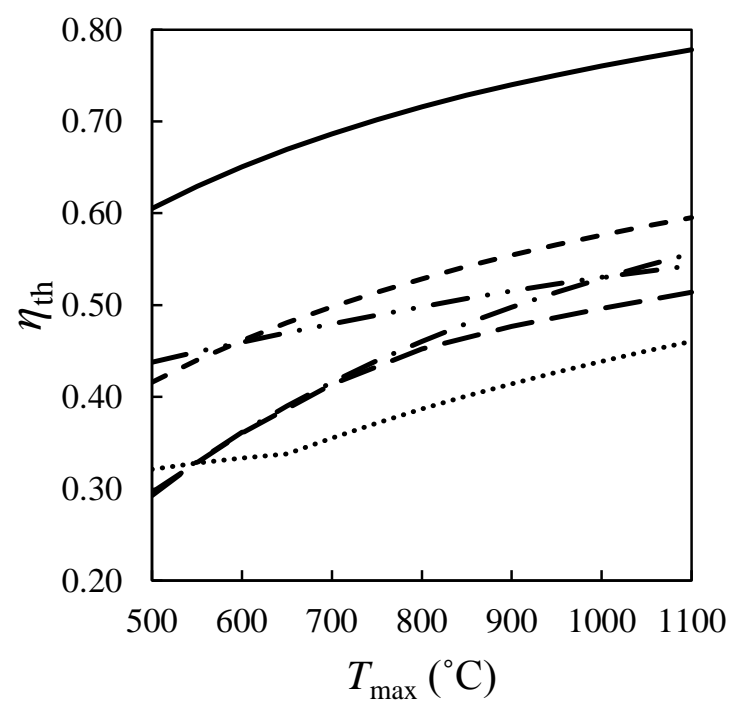

(a)

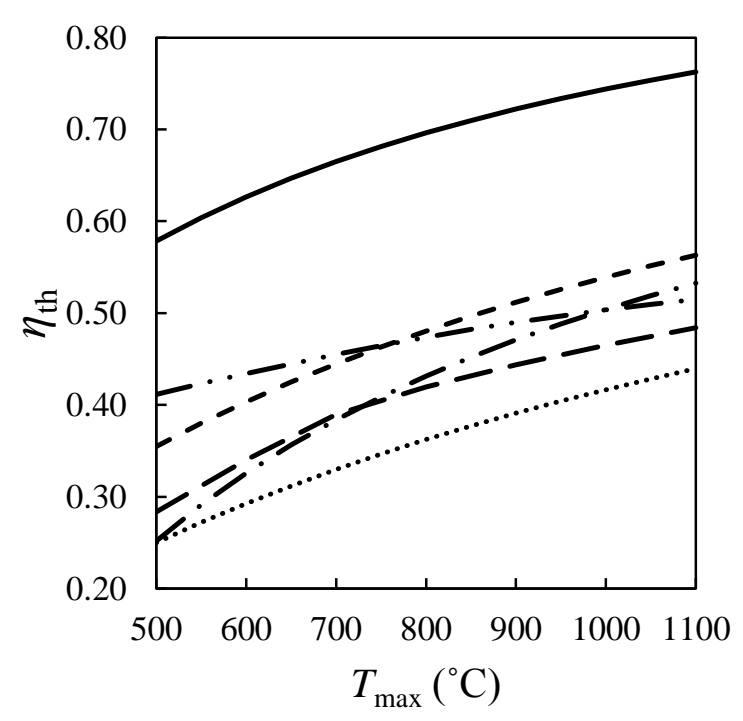

(b)

Fig. 10. Comparison of cycle performance at 20 MPa maximum pressure under (a) wet-cooling and (b) drycooling conditions.

The steam Rankine and $\mathrm{CO}_{2}$ recompression Brayton cycles give the maximum efficiency across the range of temperatures examined, with steam Rankine taking a slight advantage at the low temperature end and $\mathrm{CO}_{2}$ recompression eclipsing it after about $600{ }^{\circ} \mathrm{C}$. This suggests that applications providing temperatures up to $600{ }^{\circ} \mathrm{C}$ may be best suited to the steam Rankine configuration, while higher efficiencies can be achieved with a $\mathrm{CO}_{2}$ recompression cycle at higher temperatures. This is somewhat convenient due to the material constraints of steam 
systems as mentioned previously. Steam Rankine is seen to outperform the He-Brayton until the turbine inlet temperature exceeds approximately $1050{ }^{\circ} \mathrm{C}$. It is noted, however, that much research is needed in order to advance steam cycles to these temperatures. Therefore beyond 600 ${ }^{\circ} \mathrm{C}$, the most favorable alternative thermodynamic cycle would be the $\mathrm{CO}_{2}$ recompression Brayton followed by the He-Brayton system. Performance characteristics with dry-cooling are illustrated in Fig. 10b. Dry-cooling moves the range of steam Rankine's superiority closer to 700 ${ }^{\circ} \mathrm{C}$. However, the $50 \%$ thermal efficiency is most likely to be achieved by the $\mathrm{CO}_{2}$ recompression Brayton cycle.

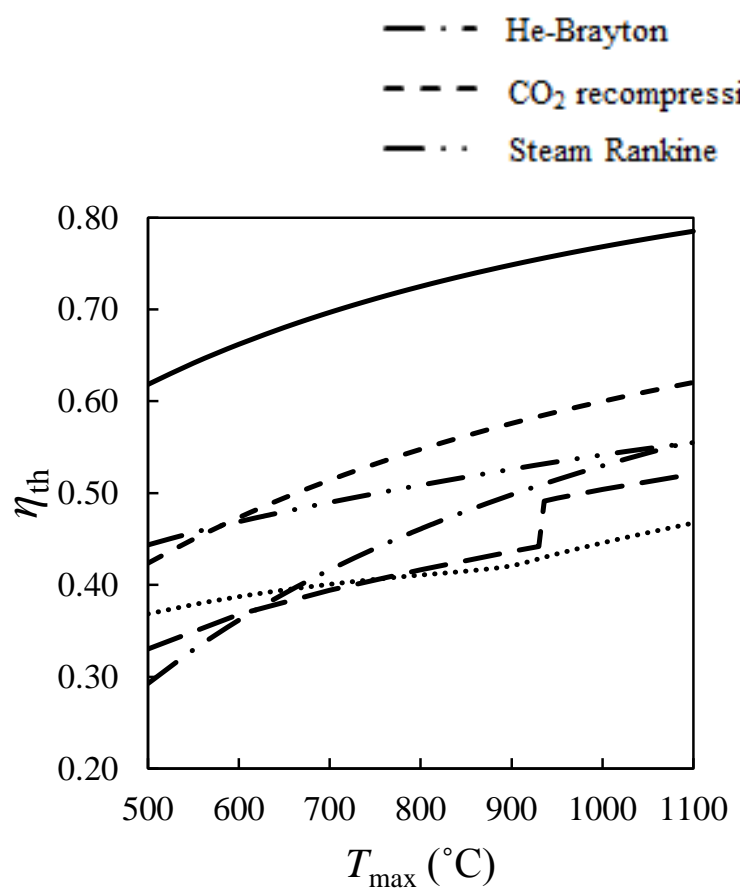

(a)
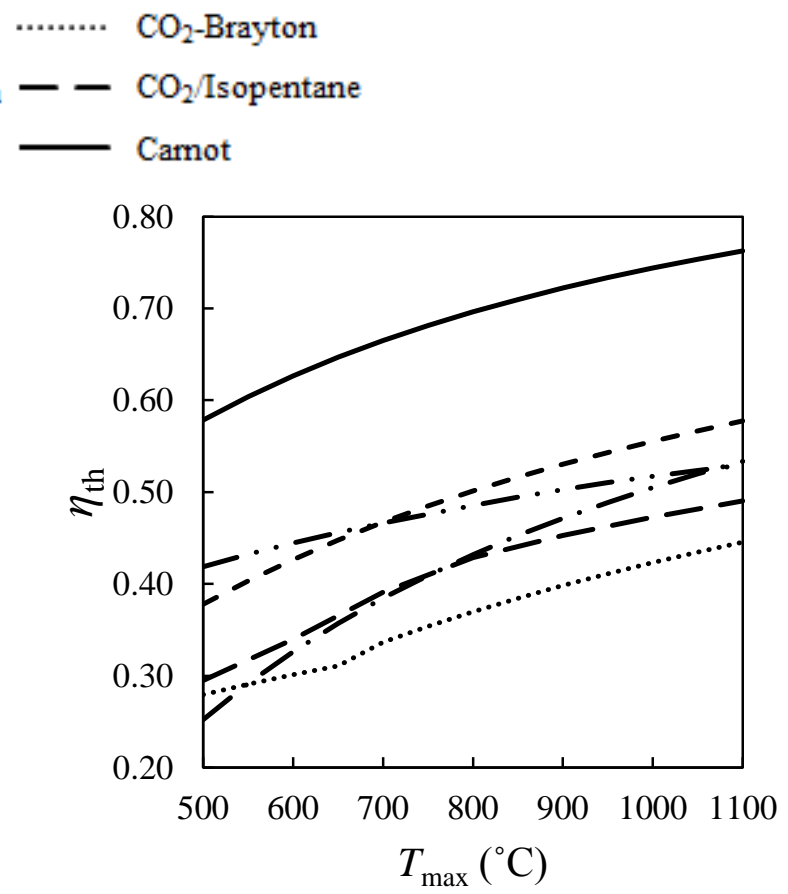

(b)

Fig. 11. Comparison of cycle performance at 30 MPa maximum pressure under (a) wet-cooling and (b) drycooling conditions.

Systems with a maximum pressure of $30 \mathrm{MPa}$ are compared in Fig. 11a and b for wet- and drycooling, respectively. At this higher maximum pressure, the $\mathrm{CO}_{2}$ recompression Brayton cycle overtakes the steam Rankine cycle as the most efficient at an earlier temperature. There is an 
interesting and obvious jump in the efficiency curve at $936{ }^{\circ} \mathrm{C}$ for the $\mathrm{CO}_{2}$-Isopentane combined cycle. This is caused by the fact that the conditions for the topping cycle were optimized before integration with the bottoming cycle. This leads to an effect similar to the regular $\mathrm{CO}_{2}$-Brayton in Fig. 6, where part of the maximum temperature range falls in the subcritical range while the rest is entirely supercritical. For supercritical conditions, the heat supplied to the bottoming cycle is at a lower temperature, which limits the potential heat transfer and total thermal efficiency.

The design of CSP systems is a complex process involving several interdependent components, including optics, solar receiver, and power block. A useful comparison includes analyzing the optimum operating temperature based on receiver and heat engine efficiencies. This has been done $[64,65]$ by maximizing the product of the Carnot efficiency and the blackbody receiver efficiency for a given concentration ratio:

$$
\eta_{\text {system }}=\eta_{\text {Carnot }} \eta_{\text {receiver }}=\left(1-\frac{T_{\text {ambient }}}{T_{\text {receiver }}}\right)\left(1-\frac{\sigma\left(T_{\text {receiver }}\right)^{4}}{C I_{\text {DNI }}}\right)
$$

where $\sigma$ is the Stefan-Boltzmann constant, $C$ is the solar concentration ratio, and $I_{\mathrm{DNI}}$ is the nominal solar flux. This relation provides an optimum receiver temperature for maximizing the system efficiency. However, use of the Carnot efficiency is unrealistic, as it represents an ideal case. In reality, the profile of thermal efficiency vs. operating temperature will depend on a complex relationship between the working fluid, cycle type, and specific component characteristics. Further, analysis of the receiver efficiency should include realistic terms such as absorptivity, emissivity, convection losses, and collector field efficiency. In order to determine the optimum operating temperature and address the deficiencies in the approach following Eq. (5), the Carnot efficiency is replaced with the individual cycle efficiency and the receiver 
efficiency based on that presented by Ho and Iverson in [18]. In this way the radiative absorption and emission behavior of the receiver is included, giving a relation for the system efficiency as:

$$
\eta_{\text {system }}=\eta_{\text {th }}\left(\alpha_{\text {receiver }}-\frac{\varepsilon_{\text {receiver }} \sigma\left(T_{\text {receiver }}\right)^{4}-h_{\text {convection }}\left(T_{\text {receiver }}-T_{\text {ambient }}\right)}{\eta_{\text {field }} C I_{\text {DNI }}}\right)
$$

It is assumed that the working fluid reaches the same temperature as the receiver. System efficiency calculated using Eq. (6) is compared for different cycle assumptions in Fig. 12a and b, for wet- and dry-cooling, respectively. Baseline values given in [18] are used for the receiver efficiency calculation and outlined in Table 5. Clearly this approach assumes a steady state condition. Methodologies exist for estimating time-variant solar irradiation which could be implemented into a more complex modeling scheme [66].

Table 5. Baseline parameter values used to calculate receiver efficiency in Eq. (6).

\begin{tabular}{ll}
\hline Parameter & Value \\
\hline$\alpha$ & 0.95 \\
\hline$\varepsilon_{\text {receiver }}$ & 0.88 \\
\hline$h_{\text {convection }}$ & $10 \mathrm{~W} / \mathrm{m}^{2}-\mathrm{K}$ \\
\hline$T_{\text {amb }}$ & $22^{\circ} \mathrm{C}$ \\
\hline$\eta_{\text {field }}$ & 0.6 \\
\hline$C$ & 900 \\
\hline$I_{\text {DNI }}$ & $800 \mathrm{~W} / \mathrm{m}^{2}$ \\
\hline
\end{tabular}




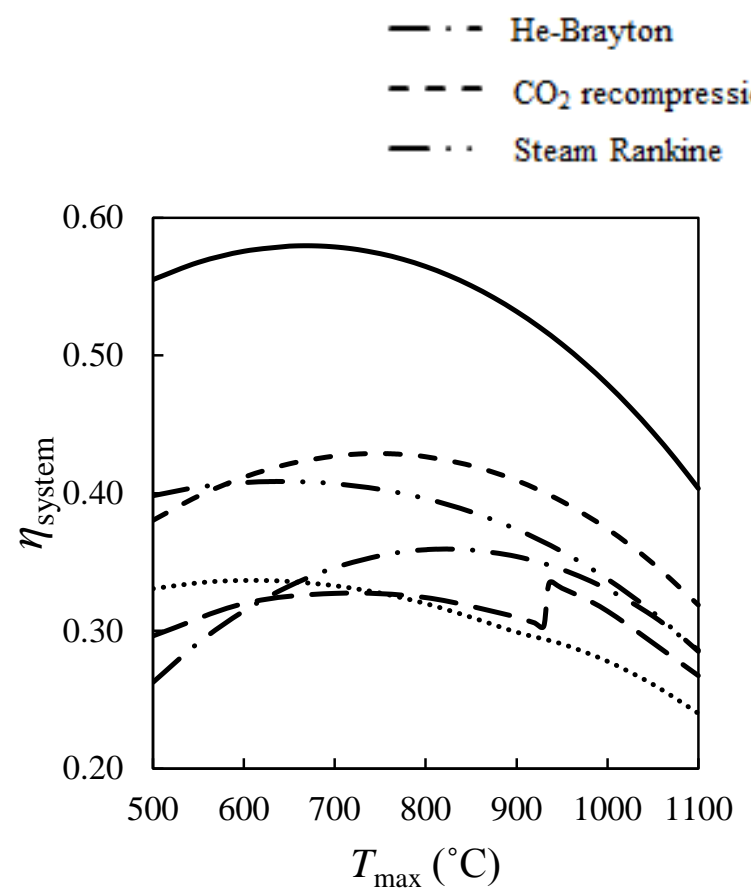

(a)
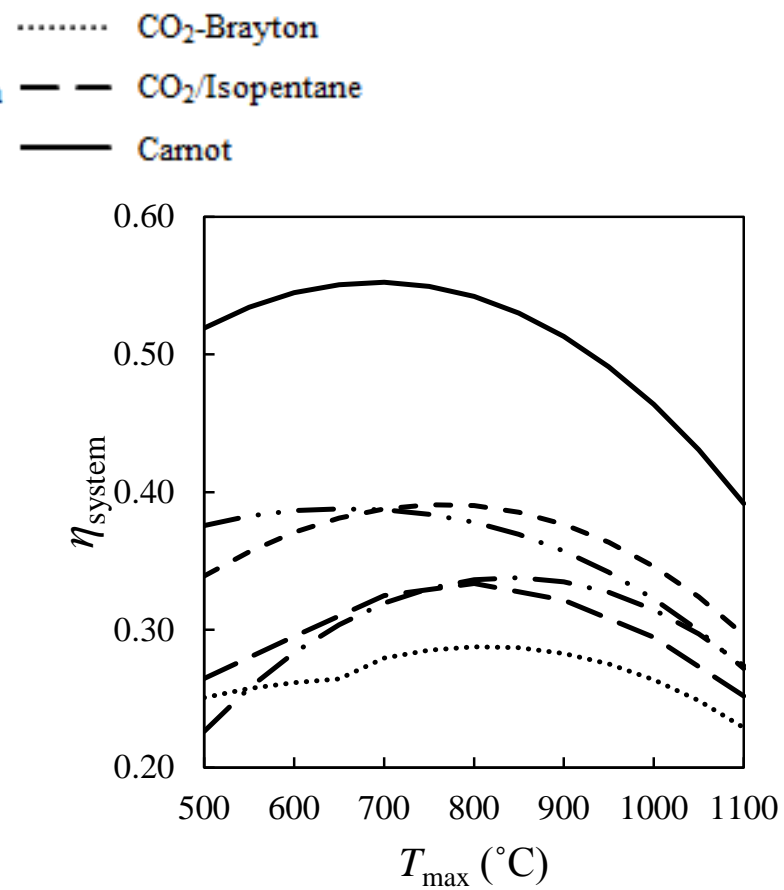

(b)

Fig. 12. System efficiency calculated from Eq. (6) for different cycles assuming 30 MPa maximum pressure for (a) wet-cooling and (b) dry-cooling conditions, and receiver parameters outlined in Table 5.

Table 6. Summary of maximum system efficiency and optimum temperature for each cycle at $30 \mathrm{MPa}$ maximum pressure under wet- and dry-cooling conditions.

\begin{tabular}{lccc|ccc} 
& \multicolumn{3}{c|}{ Wet-cooling } & \multicolumn{3}{c}{ Dry-cooling } \\
\cline { 2 - 7 } Cycle & $\begin{array}{c}\boldsymbol{T}_{\text {opt }} \\
\left({ }^{\circ} \mathbf{C}\right)\end{array}$ & $\begin{array}{c}\boldsymbol{\eta}_{\text {system,max }} \\
(-)\end{array}$ & $\begin{array}{c}\Delta \boldsymbol{T}_{\text {rel }}{ }^{*} \\
\left({ }^{\circ} \mathbf{C}\right)\end{array}$ & $\begin{array}{c}\boldsymbol{T}_{\text {opt }} \\
\left({ }^{\circ} \mathbf{C}\right)\end{array}$ & $\begin{array}{c}\boldsymbol{\eta}_{\text {system,max }} \\
(-)\end{array}$ & $\begin{array}{c}\Delta \boldsymbol{T}_{\text {rel }}{ }^{*} \\
\left({ }^{\circ} \mathbf{C}\right)\end{array}$ \\
\hline Carnot & 668 & 0.580 & 0 & 685 & 0.561 & 0 \\
\hline $\mathrm{He}-$ Brayton & 824 & 0.359 & +156 & 844 & 0.338 & +159 \\
\hline $\mathrm{CO}_{2}$-Brayton & 620 & 0.337 & -48 & 814 & 0.288 & +129 \\
\hline $\mathrm{CO}_{2}$ Recompression & 746 & 0.429 & +78 & 766 & 0.391 & +81 \\
\hline $\mathrm{CO}_{2} /$ Isopentane & 936 & 0.331 & +268 & 781 & 0.334 & +96 \\
\hline Steam & 644 & 0.409 & -24 & 659 & 0.388 & -26 \\
\hline
\end{tabular}

$* \Delta T_{\text {rel }}$ is the temperature shift in peak system efficiency relative to Carnot

While all cycles considered do attain a maximum efficiency at some temperature due to the influence of the $T^{4}$ term in the receiver efficiency relation, the temperature at which this 
maximum occurs is not consistent between the different cycles. As seen in Fig. 12, the highest system efficiency is expected to be a steam Rankine cycle in combination with a CSP plant receiver for temperatures up to approximately $575{ }^{\circ} \mathrm{C}$ and nearly $700{ }^{\circ} \mathrm{C}$ for wet- and drycooling, respectively. This crossover corresponds with the crossover observed in thermal efficiency shown in Fig. 11. Beyond these temperatures the most efficient combined cycle and receiver system is the $\mathrm{CO}_{2}$ recompression cycle. The benefit of using the $\mathrm{CO}_{2}$ recompression cycle over a steam Rankine cycle in a CSP system appears to be less when operating with drycooling. However, the peak system efficiency for the $\mathrm{CO}_{2}$ recompression cycle occurs at $746{ }^{\circ} \mathrm{C}$ and $766{ }^{\circ} \mathrm{C}$ for wet- and dry-cooling, with the receiver behavior dominating performance above these temperatures. The maximum system efficiency should be noted for development of CSP plants with the understanding that additional increases in temperature that bring about improvement in the cycle thermal efficiency may result in decreased system performance. For this reason, if temperatures above the observed system efficiency peak for a given cycle are to be pursued, improvements in the receiver performance should be the focus of system optimization. The addition of thermal storage enables this possibility in that it decouples the solar collection from the dispatch of electricity resulting in receiver optimization independent of the thermodynamic working fluid.

In the case of the combined $\mathrm{CO}_{2} /$ Isopentane cycle, the shift is as much as $268{ }^{\circ} \mathrm{C}$ for wet cooling, though this peak is present at the discontinuity due to the transition of the topping cycle to supercritical operation and would likely shift to a lower temperature if conditions were optimized for best combined thermal efficiency. Such a difference in optimum temperature can have a significant impact on the design of the solar receiver, as well as the optical field providing the concentrated flux. In particular, attention to this impact is essential when dealing with sensitive 
thermodynamic conditions such as the near-supercritical regime for $\mathrm{CO}_{2}$. The effects of transition to and from supercritical state has a sudden and dramatic impact on the overall system efficiency, which a simple Carnot relation is, by its nature, unable to predict.

\section{Conclusions}

A review of high-efficiency thermodynamic cycles and their applicability to CSP systems has been presented, followed by analyses of promising candidates, including regenerated HeBrayton, regenerated $\mathrm{CO}_{2}$-Brayton, $\mathrm{CO}_{2}$ recompression Brayton, steam Rankine, and $\mathrm{CO}_{2}-\mathrm{ORC}$ combined cycle. It is determined that steam Rankine systems may offer higher thermal efficiencies up to current material limits for steam components: about $600{ }^{\circ} \mathrm{C}$. Beyond approximately this temperature, a $\mathrm{CO}_{2}$ recompression Brayton cycle is shown to offer very high thermal efficiency, potentially even exceeding $60 \%$ at $30 \mathrm{MPa}$ and above $1000{ }^{\circ} \mathrm{C}$ with wet cooling. It has also been shown that the specific nature of the thermodynamic cycle configuration must be taken account when determining the maximum receiver operating temperature and that the Carnot assumption is not sufficient, leading to an optimum temperature shift of more than $100{ }^{\circ} \mathrm{C}$ from the case of Carnot under various conditions. The efficiency of the thermodynamic power block has previously been identified as an area with significant cost-savings potential in CSP systems. With the unique potential for energy storage among renewable resources, CSP stands to gain a significant advantage in the alternative energy portfolio if such high conversion efficiencies can be attained. 


\section{Acknowledgements}

Sandia National Laboratories is a multi-program laboratory managed and operated by Sandia Corporation, a wholly owned subsidiary of Lockheed Martin Corporation, for the U.S. Department of Energy's National Nuclear Security Administration under contract DE-AC0494AL85000. Many thanks are given to Jim Pacheco for his comments and suggestions during the preparation of this manuscript.

\section{Nomenclature}

$\begin{array}{ll}C & \text { solar concentration ratio } \\ h & \text { enthalpy, } \mathrm{kJ} / \mathrm{kg} \\ h_{\text {convection }} & \text { convection heat transfer coefficient, } \mathrm{W} / \mathrm{m}^{2} \mathrm{~K} \\ \text { HEX } & \text { heat exchanger } \\ I_{\mathrm{DNI}} & \text { nominal direct solar flux, } \mathrm{W} / \mathrm{m}^{2} \\ \dot{m} & \text { mass flow rate, } \mathrm{kg} / \mathrm{s} \\ p & \text { pressure, } \mathrm{MPa} \\ \dot{Q} & \text { heat rate, } \mathrm{W} \\ T & \text { temperature, }{ }^{\circ} \mathrm{C} \\ \dot{W} & \text { power, } \mathrm{W}\end{array}$

\section{Greek}

$\alpha_{\text {receiver }} \quad$ radiative absorptivity

$\Delta T_{\text {rel }} \quad$ temperature shift in peak system efficiency relative to Carnot, ${ }^{\circ} \mathrm{C}$

$\varepsilon_{\text {receiver }} \quad$ radiative emissivity

$\varepsilon_{\text {regen }} \quad$ regenerator effectiveness

$\eta \quad$ efficiency

$\sigma \quad$ Stefan-Boltzmann constant, $5.670 \times 10^{-8} \mathrm{~W} / \mathrm{m}^{2} \mathrm{~K}^{4}$

\section{Subscripts}




$\begin{array}{ll}(T, p) & \text { at temperature } T \text { and pressure } p \\ \text { ambient } & \text { at ambient conditions } \\ \text { bottom } & \text { related to the bottoming cycle of a combined configuration } \\ \text { Carnot } & \text { predicted by Carnot } \\ \text { combined } & \text { related to the entire combined cycle } \\ \text { compressor } & \text { related to the gas compressor } \\ \text { field } & \text { related to the heliostat field } \\ \text { HP } & \text { high-pressure } \\ \text { HT } & \text { high-temperature } \\ \text { in } & \text { inlet quantity } \\ \text { loss } & \text { drop } \\ \text { LP } & \text { low-pressure } \\ \text { LT } & \text { low-temperature } \\ \text { max } & \text { maximum } \\ \text { min } & \text { minimum } \\ \text { net } & \text { out minus in } \\ \text { opt } & \text { optimum } \\ \text { pump } & \text { related to the liquid pump } \\ \text { R } & \text { ratio } \\ \text { receiver } & \text { related to the solar receiver } \\ \text { shaft } & \text { related to the turbine-compressor shaft } \\ \text { stage } & \text { related to one stage, e.g. for intercooled compression } \\ \text { system } & \text { related to the heat engine and solar receiver } \\ \text { th } & \text { thermal } \\ \text { top } & \text { related to the topping cycle of a combined configuration } \\ \text { turbine } & \text { related to the heat engine turbine } \\ & \end{array}$

\section{References}

[1] Denholm P, Hand M. Grid flexibility and storage required to achieve very high penetration of variable renewable electricity. Energy Policy 2011;39:1817-30.

[2] Denholm P, Ela E, Kirby B, Milligan M. The role of energy storage with renewable electricity generation. NREL/TP-6A2-47187. National Renewable Energy Laboratory; 2010 .

[3] Sioshansi R, Denholm P. The value of concentrating solar power and thermal energy storage. NREL-TP-6A2-45833. National Renewable Energy Laboratory; 2010.

[4] Barlev D, Vidu R, Stroeve P. Innovation in concentrated solar power. Solar Energy Materials and Solar Cells 2011;95:2703-25. 
[5] Burgaleta Arias, S., and Ramirez, D. JI. Gemasolar, the first tower thermosolar commercial plant with molten salt storage. In: Proceedings of SolarPACES 2011, Granada, Spain: September 20-23, 2011.

[6] Caldés N, Varela M, Santamaría M, Sáez R. Economic impact of solar thermal electricity deployment in Spain. Energy Policy 2009;37:1628-36.

[7] Zhao CY, Wu ZG. Thermal property characterization of a low melting-temperature ternary nitrate salt mixture for thermal energy storage systems. Solar Energy Materials and Solar Cells 2011;95:3341-6.

[8] Goswami DY. Solar thermal power technology: Present status and ideas for the future. Energy Sources 1998;20:137-45.

[9] Kolb GJ, Ho CK, Mancini TR, Gary JA. Power Tower Technology Roadmap and Cost Reduction Plan. SAND2011-2419. Sandia National Laboratories; 2011.

[10] Finch NS, Ho CK. Stochastic modeling of power towers and evaluation of technical improvement opportunities. In: Proceedings of SolarPACES 2011, Granada, Spain: September 20-23, 2011.

[11] Tsiklauri G, Talbert R, Schmitt S, Filippov G, Bogoyavlensky R, Grishanin E, et al. Supercritical steam cycle for nuclear power plant. Nuclear Engineering and Design 2005;235:1651-64.

[12] Bolland O. A comparative evaluation of advanced combined cycle alternatives. In: Proceedings of the International Gas Turbine and Aeroengine Congress and Exhibition, Brussels, Belgium: .

[13] Chacartegui R, Muñoz de Escalona JM, Sánchez D, Monje B, Sánchez T. Alternative cycles based on carbon dioxide for central receiver solar power plants. Applied Thermal Engineering 2011;31:872-9.

[14] Mittelman G, Epstein M. A novel power block for CSP systems. Solar Energy 2010;84:1761-71.

[15] Spelling J, Favrat D, Martin A, Augsburger G. Thermoeconomic optimization of a combined-cycle solar tower power plant. Energy 2012;41:113-20.

[16] Behar O, Khellaf A, Mohammedi K. A review of studies on central receiver solar thermal power plants. Renewable and Sustainable Energy Reviews 2013;23:12-39.

[17] Siva Reddy V, Kaushik SC, Ranjan KR, Tyagi SK. State-of-the-art of solar thermal power plants-A review. Renewable and Sustainable Energy Reviews 2013;27:258-73. 
[18] Ho CK, Iverson BD. Review of high-temperature central receiver designs for concentrating solar power. Renewable and Sustainable Energy Reviews 2014;29:835-46.

[19] SunShot Initiative. Available from: (http://www1.eere.energy.gov/solar/sunshot/solar_program.html). [Accessed 05.15.12].

[20] Kribus A, Doron P, Rubin R, Karni J, Reuven R, Duchan S, et al. A multistage solar receiver: The route to high temperature. Solar Energy 1999;67:3-11.

[21] Ries H, Kribus A, Karni J. Non-isothermal receivers. Journal of Solar Energy Engineering 1995;117:259-61.

[22] Barigozzi G, Bonetti G, Franchini G, Perdichizzi A, Ravelli S. Thermal performance prediction of a solar hybrid gas turbine. Solar Energy 2012;86:2116-27.

[23] Price H, Lupfert E, Kearney D, Zarza E, Cohen G, Gee R, et al. Advances in Parabolic Trough Solar Power Technology. Journal of Solar Energy Engineering 2002;124:109-25.

[24] Zarza E, Rojas ME, Gonzalez L, Caballero JM, Rueda F. INDITEP: The first precommercial DSG solar power plant. Solar Energy 2006;80:1270-6.

[25] Pacheco JE, Moursund C, Rogers D, Wasyluk D. Conceptual Design of a $100 \mathrm{MWe}$ Modular Molten Salt Power Tower Plant. In: Proceedings of SolarPACES 2011, Granada, Spain: September 20-23, 2011.

[26] Forsberg CW, Peterson PF, Zhao H. High-Temperature Liquid-Fluoride-Salt ClosedBrayton-Cycle Solar Power Towers. Journal of Solar Energy Engineering 2007;129:1416.

[27] Wheeldon JM. Engineering and economic evaluation of $1300^{\circ} \mathrm{F}$ series ultra-supercritical pulverized coal power plants: Phase 1. 1015699. Palo Alto, CA: Electric Power Research Institute; 2008.

[28] Chen H, Goswami DY, Stefanakos EK. A review of thermodynamic cycles and working fluids for the conversion of low-grade heat. Renewable and Sustainable Energy Reviews 2010;14:3059-67.

[29] Fernández FJ, Prieto MM, Suárez I. Thermodynamic analysis of high-temperature regenerative organic Rankine cycles using siloxanes as working fluids. Energy 2011;36:5239-49.

[30] Angelino G, Invernizzi C. Binary conversion cycles for concentrating solar power technology. Solar Energy 2008;82:637-47.

[31] Iverson BD, Conboy TM, Pasch JJ, Kruizenga AM. Supercritical CO2 Brayton cycles for solar-thermal energy. Applied Energy 2013;111:957-70. 
[32] Angelino G. Perspectives for the liquid phase compression gas turbine. Journal of Engineering for Power 1967;89:229-36.

[33] Angelino G. Carbon dioxide condensation cycles for power production. Journal of Engineering for Power 1968;90:287-96.

[34] Dostal V, Hejzlar P, Driscoll MJ. The supercritical carbon dioxide power cycle: Comparison to other advanced power cycles. Nuclear Technology 2006;154:283-301.

[35] Moisseytsev A, Sienicki JJ. Investigation of alternative layouts for the supercritical carbon dioxide Brayton cycle for a sodium-cooled fast reactor. Nuclear Engineering and Design 2009;239:1362-71.

[36] Garg P, Kumar P, Srinivasan K. Supercritical carbon dioxide Brayton cycle for concentrated solar power. The Journal of Supercritical Fluids 2013;76:54-60.

[37] Ma Z, Turchi C. Advanced supercritical carbon dioxide power cycle configurations for use in concentrating solar power systems. NREL/CP-5500-50787. Golden, CO: National Renewable Energy Laboratory; 2011.

[38] Singh R, Rowlands AS, Miller S a. Effects of relative volume-ratios on dynamic performance of a direct-heated supercritical carbon-dioxide closed Brayton cycle in a solar-thermal power plant. Energy 2013;55:1025-32.

[39] Hoang HT, Corcoran MR, Wuthrich JW. Thermodynamic study of supercritical CO2 Brayton cycle concept. In: Proceedings of S-CO2 Power Cycle Symposium, RPI, Troy, NY: .

[40] Marrero IO, Lefsaker AM, Razani A, Kim KJ. Second law analysis and optimization of a combined triple power cycle. Energy Conversion and Management 2002;43:557-73.

[41] Haywood RW. Analysis of engineering cycles. 3rd ed. New York: Pergamon Press; 1991.

[42] Kehlhofer R, Bachmann R, Nielson H, Warner J. Combined-cycle gas and steam turbine power plants. 2nd ed. Tulsa, OK: Pennwell Publishing; 1999.

[43] Klimas PC, Becker M. Status of second-generation central receiver technologies. Solar Energy Materials 1991;24:162-71.

[44] McGovern RK, Smith WJ. Optimal concentration and temperatures of solar thermal power plants. Energy Conversion and Management 2012;60:226-32.

[45] Chacartegui R, Sánchez D, Muñoz JM, Sánchez T. Alternative ORC bottoming cycles for combined cycle power plants. Applied Energy 2009;86:2162-70. 
[46] Dunham MT, Lipiński W. Thermodynamic analyses of single Brayton and combined Brayton-Rankine cycles for distributed solar thermal power generation. Journal of Solar Energy Engineering 2013;135.

[47] Johnson GA. Power conversion system evaluation for the next generation nuclear plant. Nuclear Technology 2011;175:371-87.

[48] Kalina AI. Combined-cycle system with novel bottoming cycle. Journal of Engineering for Gas Turbines and Power 1984;106:737-42.

[49] Goswami DY, Vijayaraghavan S, Lu S, Tamm G. New and emerging developments in solar energy. Solar Energy 2004;76:33-43.

[50] Peng S, Hong H, Jin H, Wang Z. An integrated solar thermal power system using intercooled gas turbine and Kalina cycle. Energy 2012;44:732-40.

[51] Kribus A. A high-efficiency triple cycle for solar power generation. Solar Energy 2002;72:1-11.

[52] Ho T, Mao SS, Greif R. Comparison of the Organic Flash Cycle (OFC) to other advanced vapor cycles for intermediate and high temperature waste heat reclamation and solar thermal energy. Energy 2012;42:213-23.

[53] Carter NT, Campbell RJ. Water Issues of Concentrating Solar Power (CSP) Electricity in the U.S. Southwest. R40631. Congressional Research Service; 2009.

[54] Holbert KE, Haverkamp CJ. Impact of solar thermal power plants on water resources and electricity costs in the Southwest. In: Proceedings of the North American Power Symposium (NAPS), Starkville, Mississippi: October 4-6, 2009.

[55] Pihl E, Kushnir D, Sandén B, Johnsson F. Material constraints for concentrating solar thermal power. Energy 2012;44:944-54.

[56] Chien JC-L, Lior N. Concentrating solar thermal power as a viable alternative in China's electricity supply. Energy Policy 2011;39:7622-36.

[57] Azoumah Y, Ramdé EW, Tapsoba G, Thiam S. Siting guidelines for concentrating solar power plants in the Sahel: Case study of Burkina Faso. Solar Energy 2010;84:1545-53.

[58] Arrieta FRP, Lora EES. Influence of ambient temperature on combined-cycle power-plant performance. Applied Energy 2005;80:261-72.

[59] Klein SA. Engineering Equation Solver 2012.

[60] Kolb GJ. An Evaluation of Possible Next-Generation High-Temperature Molten-Salt Power Towers. SAND2011-9320. Albuquerque, NM: Sandia National Laboratories; 2011. 
[61] Dostal V. A supercritical carbon dioxide cycle for next generation nuclear reactors. Doctoral Thesis. Massachusetts Institute of Technology, 2004.

[62] Bathie WM. Fundamentals of Gas Turbines. 2nd ed. Hoboken, NJ: John Wiley \& Sons, Inc.; 1996.

[63] Hung TC, Shai TY, Wang SK. A review of Organic Rankine Cycles (ORCs) for the recovery of low-grade waste heat. Energy 1997;22:661-7.

[64] Romero M, Steinfeld A. Concentrating solar thermal power and thermochemical fuels. Energy \& Environmental Science 2012;5:9234-45.

[65] Fletcher E, Moen RL. Hydrogen- and oxygen from water. Science 1977;197:1050-6.

[66] Zhang HL, Baeyens J, Degrève J, Cacères G. Concentrated solar power plants: Review and design methodology. Renewable and Sustainable Energy Reviews 2013;22:466-81. 